\title{
Methane emissions in the United States, Canada, and Mexico: evaluation of national methane emission inventories and 2010-2017 sectoral trends by inverse analysis of in situ (GLOBALVIEWplus $\mathrm{CH}_{4}$ ObsPack) and satellite (GOSAT) atmospheric observations
}

\author{
Xiao Lu ${ }^{1,2,16}$, Daniel J. Jacob ${ }^{2}$, Haolin Wang ${ }^{1}$, Joannes D. Maasakkers ${ }^{3}$, Yuzhong Zhang ${ }^{2,4,5}$, \\ Tia R. Scarpelli ${ }^{2}$, Lu Shen ${ }^{2}$, Zhen $\mathbf{Q u}^{2}$, Melissa P. Sulprizio ${ }^{2}$, Hannah Nesser ${ }^{2}$, A. Anthony Bloom ${ }^{6}$, \\ Shuang $\mathrm{Ma}^{6}$, John R. Worden ${ }^{6}$, Shaojia Fan ${ }^{1}$, Robert J. Parker ${ }^{7,8}$, Hartmut Boesch ${ }^{7,8}$, Ritesh Gautam ${ }^{9}$, \\ Deborah Gordon $^{10,11}$, Michael D. Moran ${ }^{12}$, Frances Reuland ${ }^{13}$, Claudia A. Octaviano Villasana ${ }^{14}$, and \\ Arlyn Andrews ${ }^{15}$ \\ ${ }^{1}$ School of Atmospheric Sciences, Sun Yat-sen University, Zhuhai, Guangdong Province, China \\ ${ }^{2}$ Harvard John A. Paulson School of Engineering and Applied Sciences, Harvard University, \\ Cambridge, MA, USA \\ ${ }^{3}$ SRON Netherlands Institute for Space Research, Utrecht, the Netherlands \\ ${ }^{4}$ School of Engineering, Westlake University, Hangzhou, Zhejiang Province, China \\ ${ }^{5}$ Institute of Advanced Technology, Westlake Institute for Advanced Study, Hangzhou, \\ Zhejiang Province, China \\ ${ }^{6}$ Jet Propulsion Laboratory, California Institute of Technology, Pasadena, CA, USA \\ ${ }^{7}$ National Centre for Earth Observation, University of Leicester, Leicester, UK \\ ${ }^{8}$ Earth Observation Science, Department of Physics and Astronomy, University of Leicester, Leicester, UK \\ ${ }^{9}$ Environmental Defense Fund, Washington, DC, USA \\ ${ }^{10}$ RMI, New York, NY, USA \\ ${ }^{11}$ Watson Institute for International and Public Affairs, Brown University, Providence, RI, USA \\ ${ }^{12}$ Environment and Climate Change Canada, Toronto, ON, Canada \\ ${ }^{13}$ RMI, Boulder, CO, USA \\ ${ }^{14}$ Instituto Nacional de Ecología y Cambio Climático (INECC), Mexico City, Mexico \\ ${ }^{15}$ National Oceanic and Atmospheric Administration, Earth System Research Laboratory, Boulder, CO, USA \\ ${ }^{16}$ Guangdong Provincial Observation and Research Station for Climate Environment and Air Quality Change in \\ the Pearl River Estuary, Zhuhai, Guangdong Province, China
}

Correspondence: Xiao Lu (luxiao25@mail.sysu.edu.cn)

Received: 10 August 2021 - Discussion started: 19 August 2021

Revised: 12 November 2021 - Accepted: 29 November 2021 - Published: 12 January 2022

Abstract. We quantify methane emissions and their 2010-2017 trends by sector in the contiguous United States (CONUS), Canada, and Mexico by inverse analysis of in situ (GLOBALVIEWplus $\mathrm{CH}_{4}$ ObsPack) and satellite (GOSAT) atmospheric methane observations. The inversion uses as a prior estimate the national anthropogenic emission inventories for the three countries reported by the US Environmental Protection Agency (EPA), Environment and Climate Change Canada (ECCC), and the Instituto Nacional de Ecología y Cambio Climático (INECC) in Mexico to the United Nations Framework Convention on Climate Change (UNFCCC) and thus serves as an evaluation of these inventories in terms of their magnitudes and trends. Emissions are optimized with a Gaussian mixture model $(\mathrm{GMM})$ at $0.5^{\circ} \times 0.625^{\circ}$ resolution and for individual years. Optimization is 
done analytically using lognormal error forms. This yields closed-form statistics of error covariances and information content on the posterior (optimized) estimates, allows better representation of the high tail of the emission distribution, and enables construction of a large ensemble of inverse solutions using different observations and assumptions. We find that GOSAT and in situ observations are largely consistent and complementary in the optimization of methane emissions for North America. Mean 2010-2017 anthropogenic emissions from our base GOSAT + in situ inversion, with ranges from the inversion ensemble, are $36.9(32.5-37.8) \mathrm{Tg} \mathrm{a}^{-1}$ for CONUS, 5.3 (3.6-5.7) $\mathrm{Tg} \mathrm{a}^{-1}$ for Canada, and $6.0(4.7-6.1) \mathrm{Tg} \mathrm{a}^{-1}$ for Mexico. These are higher than the most recent reported national inventories of $26.0 \mathrm{Tg} \mathrm{a}^{-1}$ for the US (EPA), $4.0 \mathrm{Tg} \mathrm{a}^{-1}$ for Canada (ECCC), and $5.0 \mathrm{Tg} \mathrm{a}^{-1}$ for Mexico (INECC). The correction in all three countries is largely driven by a factor of 2 underestimate in emissions from the oil sector with major contributions from the south-central US, western Canada, and southeastern Mexico. Total CONUS anthropogenic emissions in our inversion peak in 2014, in contrast to the EPA report of a steady decreasing trend over 2010-2017. This reflects offsetting effects of increasing emissions from the oil and landfill sectors, decreasing emissions from the gas sector, and flat emissions from the livestock and coal sectors. We find decreasing trends in Canadian and Mexican anthropogenic methane emissions over the 2010-2017 period, mainly driven by oil and gas emissions. Our best estimates of mean 2010-2017 wetland emissions are 8.4 (6.4-10.6) $\mathrm{Tg} \mathrm{a}^{-1}$ for CONUS, $9.9(7.8-12.0) \mathrm{Tg} \mathrm{a}^{-1}$ for Canada, and 0.6 (0.4-0.6) $\mathrm{Tg} \mathrm{a}^{-1}$ for Mexico. Wetland emissions in CONUS show an increasing trend of $+2.6(+1.7$ to +3.8$) \% \mathrm{a}^{-1}$ over $2010-2017$ correlated with precipitation.

\section{Introduction}

Atmospheric methane $\left(\mathrm{CH}_{4}\right)$ is the most important anthropogenic greenhouse gas after carbon dioxide $\left(\mathrm{CO}_{2}\right)$. Natural emissions are mainly from wetlands. Anthropogenic emissions are from many sectors including the oil and gas supply chain, coal mining, livestock, and waste management. Individual countries must report their anthropogenic methane emissions by sector to the United Nations in accordance with the United Nations Framework Convention on Climate Change (UNFCCC, 1992). These national emission inventories are mainly constructed by bottom-up methods as the product of activity data and emission factors, following methodological guidelines from the Intergovernmental Panel on Climate Change (IPCC). The emission factors are highly variable and have large uncertainties, leading to errors in estimating national emissions, their trends, and the contributions of different sectors (Kirschke et al., 2013; Saunois et al., 2020). Top-down methods involving inversion of atmospheric methane observations can usefully diagnose these errors (Houweling et al., 2017). Here, we use an inverse analysis of 2010-2017 in situ and satellite observations of atmospheric methane over North America to evaluate national emission inventories and their trends by sector for the United States (US), Canada, and Mexico.

US anthropogenic methane emissions are reported yearly by the US Environmental Protection Agency (EPA, 2021) as part of the Inventory of US Greenhouse Gas Emissions and Sinks (GHGI). Methane emissions for the year 2012, from the 2016 version of this inventory (EPA, 2016), were spatially allocated on a $0.1^{\circ} \times 0.1^{\circ}(10 \times 10 \mathrm{~km})$ grid by Maasakkers et al. (2016) to enable its evaluation using top-down methods. Results using analysis of atmospheric methane measurements from ground, aircraft, and satellite platforms show larger methane emissions than reported in the GHGI, particularly for the oil and gas industry (Alvarez et al., 2018; Zhang et al., 2020; Lu et al., 2021; Maasakkers et al., 2021; Qu et al., 2021) and for livestock (Lu et al., 2021; Yu et al., 2021). Atmospheric observations also suggest an increasing trend of US anthropogenic emissions over the past decade (Turner et al., 2016; Sheng et al., 2018a; Lan et al., 2019; Maasakkers et al., 2021), while the GHGI indicates a decrease (EPA, 2021).

Anthropogenic methane emissions for Canada are reported yearly by Environment and Climate Change Canada (ECCC, 2020a; 2021) as part of the National Inventory Report (NIR). Atmospheric observations again indicate an underestimate of emissions from oil and gas production (Atherton et al., 2017; Johnson et al., 2017; Chan et al., 2020; Baray et al., 2021; Lu et al., 2021; Tyner and Johnson, 2021) but a decrease in these emissions over the past decade (Lu et al., 2021; Maasakkers et al., 2021). Scarpelli et al. (2021) recently allocated the ECCC NIR (ECCC 2020a) for the year 2018 on a $0.1^{\circ} \times 0.1^{\circ}$ grid, and our work is the first to use it in an inverse analysis.

Mexico's anthropogenic methane emissions are reported by the Instituto Nacional de Ecología y Cambio Climático (INECC) in Mexico's National Inventory of Greenhouse Gases and Compounds (INEGyCEI) for selected years (INECC and SEMARNAT, 2018). The last communication to the UNFCCC was in 2015, and this inventory was allocated to a $0.1^{\circ} \times 0.1^{\circ}$ grid by Scarpelli et al. (2020). A recent inverse analysis of satellite data finds oil and gas emissions to be underestimated by a factor of 2 over eastern Mexico (Shen et al., 2021). 
The above top-down studies, except for Baray et al. (2021) and Lu et al. (2021), used either in situ or satellite observations but not both. Satellite observations have better data coverage but are less sensitive to emissions (Turner et al., 2018) and have larger uncertainties, particularly at high latitudes. In a previous inverse analysis (Lu et al., 2021), we showed that in situ and satellite observations provide complementary global information for inverse analyses of methane emissions. That inversion was conducted at $4^{\circ} \times 5^{\circ}$ resolution, which is too coarse for specific evaluation of national inventories.

Here we apply extensive in situ observations from surface sites, towers, ships, and aircraft (GLOBALVIEWplus $\mathrm{CH}_{4}$ ObsPack data compilation) together with the Greenhouse Gases Observing Satellite (GOSAT) observations in an inverse analysis for 2010-2017 to optimize methane emissions and their year-to-year variability at up to $0.5^{\circ} \times 0.625^{\circ}$ resolution for North America. We use as prior estimates the gridded national emission inventories from the EPA (US), ECCC (Canada), and INECC (Mexico) so that our results can inform inventory improvement planning at the emission sector level. Following Lu et al. (2021), we use an analytical inversion method that provides closed-form characterization of error statistics and information content on the inverse solution and that also allows us to quantitatively compare the information from the in situ and satellite observations.

\section{Methods}

We use methane observations from the GLOBALVIEWplus $\mathrm{CH}_{4}$ ObsPack in situ data (Sect. 2.1) and/or GOSAT satellite retrievals (Sect. 2.2) with the GEOS-Chem chemical transport model (Sect. 2.4) as the forward model to optimize a state vector of mean methane emissions for individual years (Sect. 2.3) covering the North American continent at a spatial resolution of up to $0.5^{\circ} \times 0.625^{\circ}$. We derive posterior estimates of the state vector and the associated error covariance matrix by analytical solution to the Bayesian optimization problem (Sect. 2.5). Our base inversion uses GOSAT + in situ observations and our best choices of inversion parameters. We also present results from an ensemble of sensitivity inversions using observation subsets (in situ or GOSAT) and varying inversion parameter assumptions (e.g., different error distributions). We attribute inversion results to different methane emission sectors with the methodology described in Sect. 2.6.

\subsection{In situ methane observations}

We use the comprehensive database of in situ (surface, tower, shipboard, and aircraft) methane observations over North America for 2010-2017 from the GLOBALVIEWplus $\mathrm{CH}_{4}$ ObsPack v1.0 product compiled by the National Oceanic and Atmospheric Administration (NOAA) Global Monitoring Laboratory (Cooperative Global Atmospheric Data In- tegration Project, 2019). Following Lu et al. (2021), data from surface and tower sites are sampled only during daytime (10:00-16:00 LT) and averaged as daytime mean values on individual days for use in the inversion. For sites with standard deviations larger than $30 \mathrm{ppb}$, we exclude data points that depart by more than 2 standard deviations from the mean because such local extreme conditions are difficult to simulate with the chemical transport model. For other sites we exclude data points that depart by more than 3 standard deviations from the mean. We also exclude aircraft measurements higher than $9 \mathrm{~km}$ a.s.l. as these measurements would have weak sensitivity to surface fluxes.

The in situ observations thus include 49742 data points from surface sites, 15285 from towers, 56 from ship cruises, and 26620 from aircraft campaigns over North America and adjacent waters (Fig. 1a). The number of available in situ observations per year increases from 10830 in 2010 to 13593 in 2017. All these in situ data points are used in the base inversion to optimize methane emissions for individual years. We also conduct sensitivity inversions by only using surface and tower sites with continuous 8-year records for trend analyses.

\subsection{GOSAT satellite methane observations}

The GOSAT satellite launched in 2009 measures the backscattered solar radiation from a sun-synchronous orbit at around 13:00 LT (Kuze et al., 2016). Methane is retrieved in the $1.65 \mu \mathrm{m}$ shortwave infrared absorption band. We use the column-averaged dry-air methane mixing ratios from the University of Leicester version 9.0 Proxy $\mathrm{XCH}_{4}$ retrieval (Parker et al., 2020a). Comparison with ground-based methane observations from the Total Carbon Column Observing Network (TCCON) shows that the retrieval has a single-observation precision of $13 \mathrm{ppb}$ and an overall global bias of $9 \mathrm{ppb}$ that is removed from the Proxy $\mathrm{XCH}_{4}$ data (Parker et al., 2020a). Here we use a total of 205875 (25 734 per year on average) GOSAT retrievals for 2010-2017 over North America in the inversion, excluding glint data over the oceans and data poleward of $60^{\circ}$, which are not representatively sampled and for which errors are large (Fig. 1b).

\subsection{Prior emission inventories}

We use as prior estimates of anthropogenic methane emissions the gridded versions of the official national inventories for the US (EPA, 2016), Canada (ECCC, 2020a), and Mexico (INECC and SEMARNAT, 2018) (Maasakkers et al., 2016; Scarpelli et al., 2020, 2021). These emissions are listed in Table 1 for individual countries, and the spatial distributions for major sectors are shown in Fig. 2. We assume no year-to-year trend in the prior emissions so that trends from the inversion are solely driven by observations. Prior anthropogenic emissions for the contiguous US (CONUS) are 28.7 $\mathrm{Tg} \mathrm{a}^{-1}$. Anthropogenic US emissions outside CONUS 
(a) In situ methane

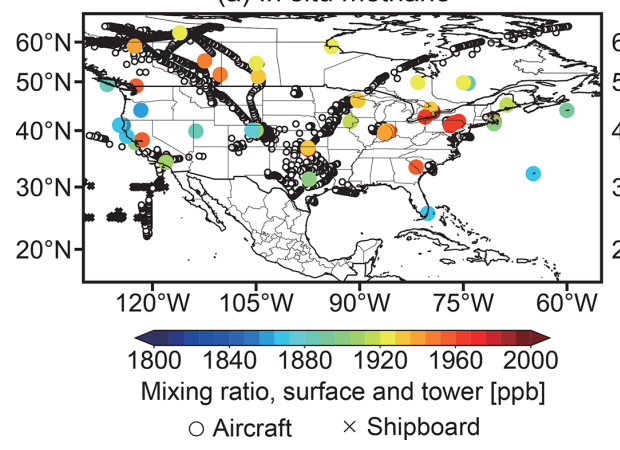

(b) GOSAT methane

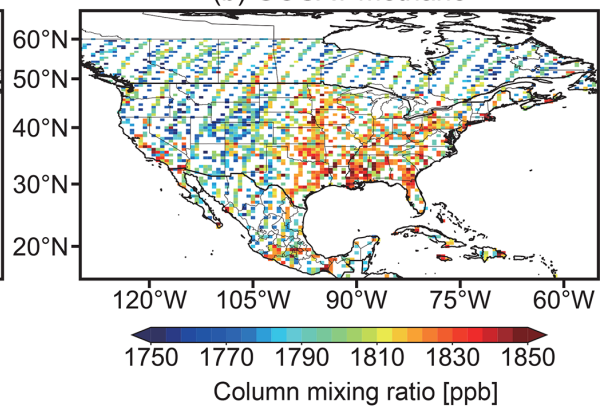

Figure 1. Methane observations over North America used in the inversion. The observations are from the in situ GLOBALVIEWplus $\mathrm{CH}_{4}$ ObsPack data product and from the GOSAT satellite instrument. Mixing ratios shown for surface, tower, and GOSAT observations are means for 2010-2017. Aircraft and shipboard observation locations are shown as additional symbols. The GOSAT data are dry column mixing ratios from the University of Leicester version 9 Proxy $\mathrm{XCH}_{4}$ retrieval (Parker et al., 2020a) and are averaged here on the $0.5^{\circ} \times 0.625^{\circ}$ GEOS-Chem model grid.

(mostly Alaska, not optimized in the inversion) account for only $0.3 \mathrm{Tg} \mathrm{a}^{-1}$ according to Maasakkers et al. (2016). The latest GHGI report from the EPA (2021) gives mean emissions of $26.0 \mathrm{Tg} \mathrm{a}^{-1}$ for 2010-2017. Prior anthropogenic emissions for Canada are $3.7 \mathrm{Tg} \mathrm{a}^{-1}$. The most recent 2021 version of the ECCC NIR gives a mean of $4.0 \mathrm{Tga}^{-1}$ for 2010-2017 (ECCC, 2021). Mexico anthropogenic emissions are $5.0 \mathrm{Tg} \mathrm{a}^{-1}$, and 2015 is the latest available year from INECC.

Prior methane emissions from wetlands are the $0.5^{\circ} \times 0.5^{\circ}$ gridded mean monthly values for 2010-2017 from the nine highest-performance members of the WetCHARTs v1.3.1 inventory ensemble (Ma et al., 2021), selected for their fit to the global GOSAT inversion results of Zhang et al. (2021). This choice of prior estimate effectively corrects the large overestimates of wetland emissions for North America previously found in inversions of GOSAT and aircraft data when using the overall mean of the WetCHARTs v1.0 ensemble (Sheng et al., 2018b; Maasakkers et al., 2021). We do not include interannual variability from WetCHARTs because it is highly uncertain and we prefer to have it informed by the observations. Unlike in our global inversion (Lu et al., 2021), we do not optimize the relative seasonal variation of wetland emissions and instead have it imposed by the prior estimate (Parker et al., 2020b). Prior estimates of open fire emissions are the daily values for individual years from the Global Fire Emissions Database (GFED) version 4s (van der Werf et al., 2017). Other small natural emissions (seepages, termites) are as described in Lu et al. (2021).

\subsection{The GEOS-Chem forward model}

We use the nested version of the GEOS-Chem 12.5.0 chemical transport model (http://geos-chem.org, last access: 6 April 2021) (Wecht et al., 2014) as the forward model for the inversion. The model is driven by MERRA-2 re-analysis meteorological fields at their native $0.5^{\circ} \times 0.625^{\circ}$ resolution (Gelaro et al., 2017). Methane loss from atmospheric oxidation is as described in Lu et al. (2021) but is inconsequential here because it is negligibly slow compared to the timescale for ventilation of the North American domain. Soil uptake of methane is from the MeMo model v1.0 (Murguia-Flores et al., 2018) but is very small and therefore not optimized in the inversion.

The GEOS-Chem model simulation is conducted at $0.5^{\circ} \times$ $0.625^{\circ}$ resolution over the North America domain (130$55^{\circ} \mathrm{W}, 15-65^{\circ} \mathrm{N}$ ) (Fig. 1) for the 2010-2017 period, with dynamic boundary conditions archived every $3 \mathrm{~h}$ from a global 2010-2017 simulation at $4^{\circ} \times 5^{\circ}$ resolution using methane emissions and sinks previously optimized with GOSAT observations ( $\mathrm{Lu}$ et al., 2021). This means that GOSAT observations over North America are used twice: once for the global inversion (along with other observations worldwide) and once for the North American inversion, but this is inconsequential because the sole purpose of the global optimization is to avoid biases in boundary conditions that would cause spurious corrections to emissions within the inversion domain (Wecht et al., 2014). Lu et al. (2021) show that their optimized simulation is unbiased in comparison to global zonal mean observations for 2010-2017, but we still find some residual biases for individual years up to $5 \mathrm{ppbv}$. We therefore optimize the mean boundary conditions for individual years on each side of the domain (north, south, west, east) as part of the North American inversion. The initial methane concentration fields on 1 January 2010 are from $\mathrm{Lu}$ et al. (2021), which have been adjusted to have an unbiased 
Table 1. (a) Mean 2010-2017 methane emissions for the contiguous US (CONUS).

\begin{tabular}{lrrr}
\hline & Prior $^{\mathrm{a}}$ & Posterior $^{\mathrm{b}}$ & Sensitivity $^{\mathrm{c}}$ \\
\hline Total sources $\left[\mathrm{Tg} \mathrm{a}^{-1}\right]$ & 36.8 & $46.3(40.2-48.4)$ & 0.72 \\
\hline Anthropogenic sources & $28.7^{\mathrm{d}}$ & $36.9(32.5-37.8)$ & 0.55 \\
\hline Livestock & 9.2 & $10.6(9.2-11.8)$ & 0.43 \\
Oil & 2.3 & $4.6(3.0-4.7)$ & 0.43 \\
Natural gas & 6.8 & $9.9(8.1-10.5)$ & 0.42 \\
Coal mining & 2.9 & $2.8(2.4-3.5)$ & 0.44 \\
Landfills & 5.8 & $7.2(6.0-7.6)$ & 0.34 \\
Wastewater & 0.70 & $0.63(0.56-0.74)$ & 0.57 \\
Rice cultivation & 0.48 & $0.65(0.49-0.68)$ & 0.33 \\
Other anthropogenic & 0.46 & $0.45(0.44-0.54)$ & 0.30 \\
\hline Natural sources & 8.6 & $9.5(7.4-11.5)$ & 0.64 \\
\hline Wetlands & 7.5 & $8.4(6.4-10.6)$ & 0.57 \\
Open fires & 0.16 & $0.17(0.15-0.24)$ & 0.43 \\
Termites & 0.59 & $0.63(0.57-0.76)$ & $<0.1$ \\
Seeps & 0.28 & $0.27(0.23-0.35)$ & 0.14 \\
\hline
\end{tabular}

\footnotetext{
a Prior estimates for the inversion. Anthropogenic emissions are from the Environmental Protection Agency (EPA) Inventory of US Greenhouse Gas Emissions and Sinks (GHGI) for the year 2012 as reported by the EPA (2016). Wetland emissions are the 2010-2017 mean of the high-performance subset of the WetCHARTs ensemble (Ma et al., 2021). Open fire emissions are from GFEDv4s (van der Werf et al., 2017). Termite and seep emissions are as described in Lu et al. (2021).

$\mathrm{b}$ Results from the base inversion of GOSAT and GLOBALVIEWplus data, with the range from the inversion ensemble and from the two sectoral attribution methods ( 66 total ensemble members) in parentheses.

${ }^{c}$ Sensitivity of the posterior estimate to the observations as diagnosed by the diagonal elements of the averaging kernel matrix, ranging from 0 (no sensitivity, posterior equal to prior) to 1 (full sensitivity, posterior fully determined by the observations). Values are from the base inversion

for the year 2015. Results for other years show similar values. See Sect. 2.6 for more details.

$\mathrm{d}$ The most recent EPA GHGI report (EPA, 2021) gives a mean anthropogenic emission of

26.0 $\mathrm{Tg} \mathrm{a}^{-1}$ for 2010-2017. Anthropogenic US emissions outside CONUS (mostly Alaska) account for only $0.3 \mathrm{Tg} \mathrm{a}^{-1}$ according to the EPA (Maasakkers et al., 2016) and are not optimized in the inversion.
}

zonal mean relative to GOSAT observations such that model discrepancies with observations over our 2010-2017 simulation period can be attributed to model errors in emissions instead of errors in initial conditions.

\subsection{Inversion procedure}

Our state vector $\boldsymbol{x}$ to be optimized in the inversion includes spatially resolved emissions in North America and boundary conditions for each year of 2010-2017. Although we could technically optimize methane emissions for each of the $0.5^{\circ} \times 0.625^{\circ}$ native model grid elements, the observations do not have sufficient coverage to constrain emissions everywhere at that resolution, and doing so would introduce large smoothing errors in the inversion (Wecht et al., 2014). Following Turner and Jacob (2015) and Maasakkers et al. (2021), we use instead a Gaussian mixture model (GMM) to determine the emission patterns that can be constrained effectively by the inversion. This is done by projecting the native-resolution methane emissions onto 600 Gaussian functions optimized to fit the location, magnitude, and distribution of methane emissions for different sectors as given by the prior estimates. Optimal construction of the GMM aggregates regions with weak or homogeneous emissions while preserving native resolution for strong localized source regions. The Gaussian functions overlap, providing additional high-resolution structure in the inverse solution on the $0.5^{\circ} \times 0.625^{\circ}$ native grid. The state vector $\boldsymbol{x}$ for individual years is defined as the emission of each of the 600 Gaussians, plus the correction to the model boundary conditions as described earlier, for a total dimension $n=604$.

The inversion finds the optimal estimate of $x$ by minimizing the Bayesian cost function $J(\boldsymbol{x})$ (Brasseur and Jacob, 2017):

$$
\begin{aligned}
J(x)= & \left(x-x_{\mathbf{A}}\right)^{T} \mathbf{S}_{\mathbf{A}}^{-1}\left(x-x_{\mathbf{A}}\right) \\
& +\gamma(\boldsymbol{y}-\mathbf{F}(\boldsymbol{x}))^{T} \mathbf{S}_{\mathbf{O}}^{-1}(\boldsymbol{y}-\mathbf{F}(x)),
\end{aligned}
$$

where $\boldsymbol{x}_{\mathrm{A}}$ is the prior estimate of $\boldsymbol{x}, \mathbf{S}_{\mathbf{A}}$ denotes the prior error covariance matrix, $\boldsymbol{y}$ is the observation vector, $\mathbf{S}_{\mathbf{O}}$ denotes the observation error covariance matrix, $\gamma$ is a regularization factor (see below), and $\mathbf{F}(\boldsymbol{x})$ represents the GEOS-Chem simulation of $\boldsymbol{y}$. The GEOS-Chem forward model $\mathbf{F}(\boldsymbol{x})$ as imple- 
Table 1. (c) Mean 2010-2017 methane emissions for Mexico.

\begin{tabular}{|c|c|c|c|}
\hline & Prior $^{\mathrm{a}}$ & Posterior $^{b}$ & Sensitivity $^{\mathrm{c}}$ \\
\hline Total sources $\left[\mathrm{Tg} \mathrm{a}^{-1}\right]$ & 5.8 & $6.8(5.4-6.9)$ & 0.40 \\
\hline Anthropogenic sources & 5.0 & $6.0(4.7-6.1)$ & 0.41 \\
\hline Livestock & 2.3 & $2.5(2.0-2.6)$ & 0.24 \\
\hline Oil & 0.44 & $0.84(0.42-0.85)$ & 0.20 \\
\hline Natural gas & 0.34 & $0.42(0.36-0.53)$ & 0.44 \\
\hline Coal mining & 0.28 & $0.26(0.26-0.52)$ & 0.80 \\
\hline Landfills & 0.77 & $1.0(0.67-1.0)$ & 0.30 \\
\hline Wastewater & 0.69 & $0.80(0.65-0.86)$ & 0.14 \\
\hline Rice cultivation & $<0.1$ & $<0.1$ & $<0.1$ \\
\hline Other anthropogenic & 0.13 & $0.14(0.12-0.16)$ & 0.10 \\
\hline Natural sources & 0.79 & $0.83(0.64-0.89)$ & 0.10 \\
\hline Wetlands & 0.52 & $0.57(0.43-0.60)$ & $<0.1$ \\
\hline Open fires & 0.14 & $0.14(0.10-0.16)$ & $<0.1$ \\
\hline Termites & 0.13 & $0.12(0.10-0.14)$ & $<0.1$ \\
\hline Seeps & $<0.1$ & $<0.1$ & $<0.1$ \\
\hline \multicolumn{4}{|c|}{$\begin{array}{l}\text { a Prior estimates for the inversion. Anthropogenic emissions are from the National Inventory of } \\
\text { Greenhouse Gases and Compounds constructed by the Instituto Nacional de Ecología y Cambio } \\
\text { Clim/atico (INECC). Wetland emissions are the 2010-2017 mean of the high-performance } \\
\text { subset of the WetCHARTs ensemble (Ma et al., 2021). Open fire emissions are from GFEDv4s } \\
\text { (van der Werf et al., 2017). Termite and seep emissions are as described in Lu et al. (2021). } \\
\text { b Results from the base inversion of GOSAT and GLOBALVIEWplus data, with the range from } \\
\text { the inversion ensemble and from the two sectoral attribution methods ( } 66 \text { total ensemble } \\
\text { members) in parentheses. } \\
\text { c Sensitivity of the posterior estimate to the observations as diagnosed by the diagonal elements } \\
\text { of the averaging kernel matrix, ranging from } 0 \text { (no sensitivity, posterior equal to prior) to } 1 \text { (full } \\
\text { sensitivity, posterior fully determined by the observations). Values are from the base inversion } \\
\text { for the year 2015. Results for other years show similar values. See Sect. } 2.6 \text { for more details. }\end{array}$} \\
\hline
\end{tabular}

assumption, as will be described later), with no spatial error covariance so that $\mathbf{S}_{\mathbf{A}}$ is diagonal. There is necessarily some spatial covariance in the prior estimates since the Gaussians have spatial overlap, and there is also some spatial covariance in the forward model error contributing to $\mathbf{S}_{\mathbf{O}}$, but these are difficult to quantify. The former would underestimate the information content of the observations, while the latter would overestimate it. We effectively correct for this using the regularization parameter $\gamma$ as described below, and we further rely on our inversion ensemble rather than the posterior error covariance matrix to characterize the error in our posterior solution.

The standard assumption of Gaussian error statistics in the cost function of Eq. (1) is required to achieve an analytical solution but may lead to unphysical negative emissions (Miller et al., 2014) and fail to capture the heavy tail of the emission distribution (Zavala-Araiza et al., 2015; Frankenberg et al., 2016; Alvarez et al., 2018). We solve this problem by optimizing for $\ln (x)$ instead of $x$, with the error on $\ln (x)$ following a normal Gaussian distribution, i.e., lognormal errors for $\boldsymbol{x}$ (Maasakkers et al., 2019). The forward model is then nonlinear so that the solution must be solved iteratively with a transformed Jacobian matrix $\mathbf{K}_{N}^{\prime}=\partial \boldsymbol{y} / \partial \ln (\boldsymbol{x})$ at each iteration $N$. Once the original Jacobian matrix $\mathbf{K}=\partial \boldsymbol{y} / \partial \boldsymbol{x}$ for the linear model has been computed, we can derive $\mathbf{K}_{N}^{\prime}$ immediately at any iteration by $\partial y_{i} / \partial \ln \left(x_{j}\right)=x_{j} \partial y_{i} / \partial x_{j}$, where $i$ and $j$ represent the indices of the observation and state vector elements, respectively. The iterative solution is obtained with the Levenberg-Marquardt method (Rodgers, 2000) for each iteration $N$ :

$$
\begin{aligned}
\boldsymbol{x}_{N+1}^{\prime}= & \boldsymbol{x}_{N}^{\prime}+\left(\gamma \mathbf{K}_{N}^{\prime T} \mathbf{S}_{\mathbf{O}}^{-1} \mathbf{K}_{N}^{\prime}+(1+\kappa) \mathbf{S}_{\mathbf{A}}^{\prime-1}\right)^{-1} \\
& \left(\gamma \mathbf{K}_{N}^{\prime T} \mathbf{S}_{\mathbf{O}}^{-1}\left(\boldsymbol{y}-\mathbf{K} \boldsymbol{x}_{N}\right)-\mathbf{S}_{\mathbf{A}}^{\prime-1}\left(\boldsymbol{x}_{N}^{\prime}-\boldsymbol{x}_{\mathbf{A}}^{\prime}\right)\right),
\end{aligned}
$$

where $\boldsymbol{x}^{\prime}=\ln (\boldsymbol{x})$ with the initial value $\boldsymbol{x}_{\mathbf{0}}^{\prime}$ from the prior estimate, and $\kappa=10$ is a coefficient for the iterative approach to the solution (Rodgers, 2000). $\mathbf{S}_{\mathbf{A}}^{\prime}$ (with diagonal elements denoted by $s_{A}^{\prime}$ ) is the prior error covariance matrix for the inversion in log space and can be derived from the original prior error covariance matrix $\mathbf{S}_{\mathbf{A}}$ (with diagonal elements denoted by $s_{A}$ ) following (Maasakkers et al., 2019)

$s_{A}^{\prime}=\left(\frac{\left(\ln \left(\frac{x_{A}+\sqrt{s_{A}}}{x_{A}}\right)+\left|\ln \left(\frac{x_{A}-\sqrt{s_{A}}}{x_{A}}\right)\right|\right)}{2}\right)^{2}$.

We adopt as a convergence criterion that the maximum difference between $\boldsymbol{x}_{N+1}^{\prime}$ and $\boldsymbol{x}_{N}^{\prime}$ elements be smaller than 5\%o, at which point we adopt $\hat{\boldsymbol{x}}^{\prime}=\boldsymbol{x}_{N+1}^{\prime}$ as our posterior solution. 

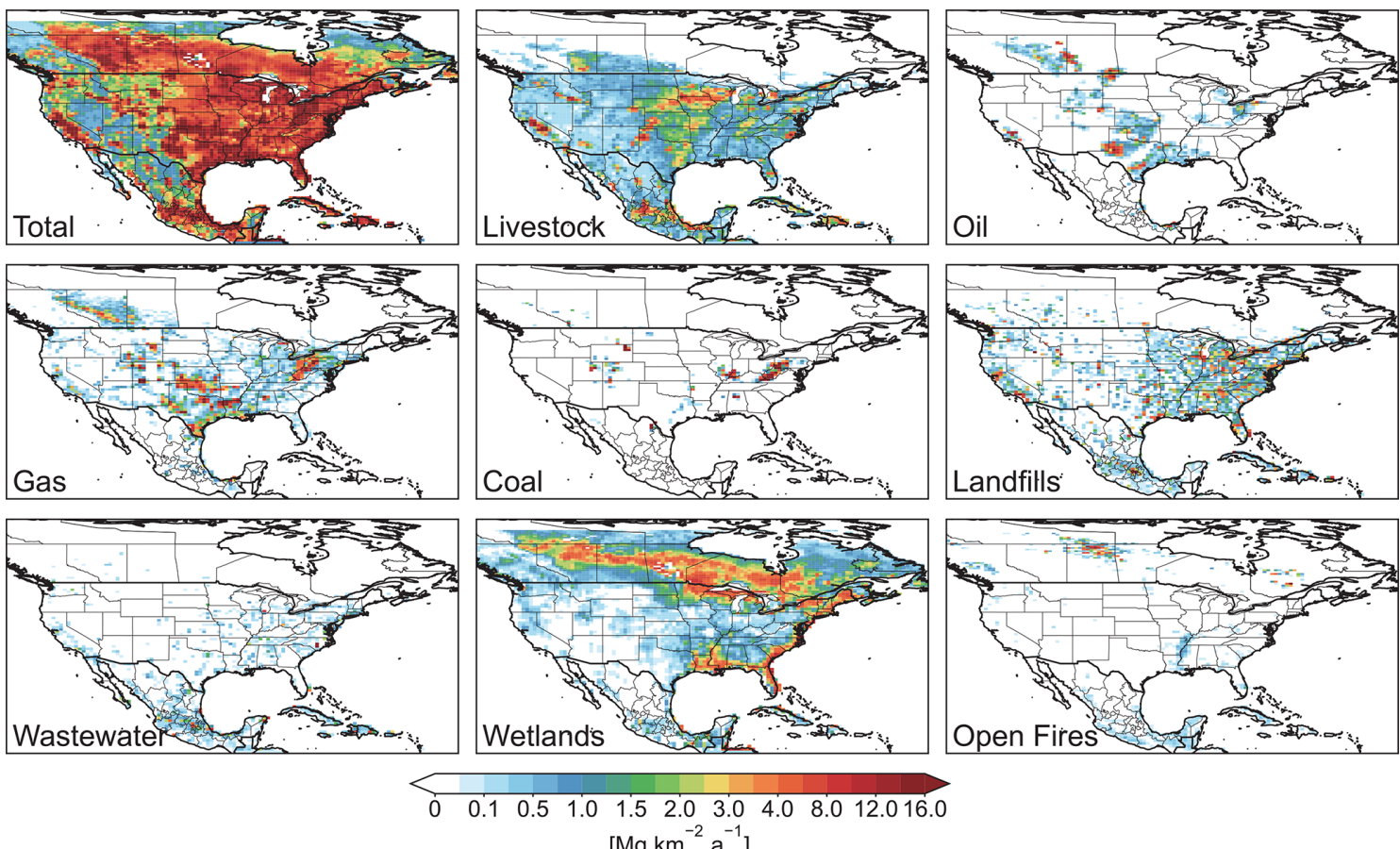

$\left[\mathrm{Mg} \mathrm{km}{ }^{-2} \mathrm{a}^{-1}\right]$

Figure 2. Prior estimates of methane emissions from individual sectors. Anthropogenic emissions are from spatially explicit versions of the EPA, ECCC, and INECC official national inventories. Wetland emissions are from the mean of the high-performance subset of the WetCHARTs inventory ensemble.

The posterior error covariance and averaging kernel matrices $\hat{\mathbf{S}}^{\prime}$ and $\mathbf{A}^{\prime}$ on the log solution are obtained by replacing $\mathbf{S}_{\mathbf{A}}$ and $\mathbf{K}$ with $\mathbf{S}_{\mathbf{A}}^{\prime}$ and $\mathbf{K}^{\prime}$ in Eqs. (3) and (4). Optimization of emissions in $\log$ space means that $\hat{\boldsymbol{x}}^{\prime}$ is a best estimate of the median of the lognormal error distribution rather than the mean. The mean values for spatial and sectoral aggregation purposes can be inferred from the properties of the lognormal distribution as $x_{j \text { (mean) }}=x_{j \text { (median) }} e^{\hat{s}_{j j}^{\prime} / 2}$, where $\hat{s}_{j j}^{\prime}$ is the corresponding diagonal element of the posterior error covariance matrix in log space, i.e., the geometric error standard deviation. The boundary conditions are still optimized with normal error distributions, assuming an error standard deviation of $10 \mathrm{ppb}$.

The above describes our base inversion. We also conduct sensitivity inversions using different error assumptions. This includes (1) using the quadrature sum of error variances for all sectors contributing to a given Gaussian with a cap of $50 \%$ following Maasakkers et al. (2021), resulting in a $43 \%$ error on average; (2)-(4) using the normal error distributions (then with the linear Jacobian matrix) with $50 \%, 95 \%$, and the quadrature sum of errors for individual Gaussians as error variances; and (5) assuming an error standard deviation of $5 \mathrm{ppb}$ for boundary conditions.

The observation error covariance matrix $\mathbf{S}_{\mathbf{O}}$ includes contributions from measurement and forward model errors. We compute it following the residual error method originally described by Heald et al. (2004) and previously used by Lu et al. (2021). A GEOS-Chem simulation with prior emission estimates yields a prior model estimate $\mathbf{F}\left(\boldsymbol{x}_{\mathrm{A}}\right)$ of concentrations at the observation points. The mean 2010-2017 discrepancy between the observations and the prior model, $\overline{\boldsymbol{y}-\mathbf{F}\left(\boldsymbol{x}_{\mathrm{A}}\right)}$, is determined for each grid cell (for GOSAT), individual observation site (surface and tower), and observation platform (shipboard and aircraft). $\overline{\boldsymbol{y}-\mathbf{F}\left(\boldsymbol{x}_{\mathbf{A}}\right)}$ is taken to represent the systematic bias in the prior emissions to be corrected in the inversion. The residual term, $\varepsilon_{\mathbf{O}}=\boldsymbol{y}-\mathbf{F}\left(\boldsymbol{x}_{\mathbf{A}}\right)-$ $\overline{\boldsymbol{y}-\mathbf{F}\left(\boldsymbol{x}_{\mathrm{A}}\right)}$, represents the random observation error including contributions from the measurements, the forward model, and the representation of the observation points on the model grid (Heald et al., 2004). The variance of $\boldsymbol{\varepsilon}_{\mathbf{O}}$ provides the diagonal terms of $\mathbf{S}_{\mathbf{O}}$. The resulting observation error standard deviations average $13 \mathrm{ppb}$ for GOSAT, $26 \mathrm{ppb}$ for surface sites, $39 \mathrm{ppb}$ for towers, $19 \mathrm{ppb}$ for ships, and $22 \mathrm{ppb}$ for aircraft. The observation error is larger for in situ than for satellite observations, even though the in situ measurements are more precise, because the forward model error is larger for vertically resolved points (particularly for surface air in source regions) than for atmospheric columns (Cusworth et al., 2018). The observation error for in situ observations is dominated by the forward model error, while that for GOSAT is dominated by the measurement error.

We do not have sufficient objective information to quantify the error correlation structure of $\mathbf{S}_{\mathbf{O}}$, and we therefore assume it to be diagonal. This may underestimate $\mathbf{S}_{\mathbf{O}}$ be- 
cause of correlated transport and source aggregation errors in the forward model, as noted above. We follow Zhang et al. (2018) to introduce a regularization factor $\gamma$ for the observation terms in the cost function $J(\boldsymbol{x})$ (Eq. 1) to avoid either overfits or underfits that would result from missing covariant (off-diagonal) structure in $\mathbf{S}_{\mathbf{O}}$ and $\mathbf{S}_{\mathbf{A}}$, respectively. Lu et al. (2021) showed that the optimal value of this regularization factor can be selected such that the sum of the $n$ prior terms in the posterior estimate of the cost function $\left(J_{A}(\hat{\boldsymbol{x}})=\left(\hat{\boldsymbol{x}}-\boldsymbol{x}_{\mathbf{A}}\right)^{T} \mathbf{S}_{\mathbf{A}}^{-1}\left(\hat{\boldsymbol{x}}-\boldsymbol{x}_{\mathbf{A}}\right)\right)$ has a value $\approx n$, which is the expected value from the chi-square distribution with $n$ degrees of freedom. Here we determine the regularization factor $\gamma$ separately for in situ and GOSAT data following Lu et al. (2021) and find that $\gamma=1$ is best for both. We also conduct a sensitivity inversion using $\gamma=0.5$ for the GOSAT observation terms (while keeping $\gamma=1$ for in situ data terms in the joint inversion) as adopted in Maasakkers et al. (2021).

Table 2 summarizes the settings of our base inversion (in bold) and the inversion ensemble. The ensemble comprises 33 inversions using the different combinations of settings in the table. The base inversion including GOSAT and in situ data represents our best estimate, but we will compare it prominently to the GOSAT-only and in-situ-only inversions with the same inversion parameters in order to evaluate the contributions from the different observing platforms for optimizing emissions. We will use the other ensemble members to discuss the sensitivity of inversion results to the choices of observations and inversion parameters, as well as to define the range of uncertainty in the inversion results.

\subsection{Sectoral attribution and aggregation of inversion results}

The inversion returns the posterior estimates of mean emissions for each of the Gaussians, and we allocate these emissions to the native $0.5^{\circ} \times 0.625^{\circ}$ model grid by summing the contributions of all Gaussians on the grid. This defines a correction factor $f_{0}$ to total prior emissions for each $0.5^{\circ} \times 0.625^{\circ}$ grid cell and including the contributions from all $q$ emission sectors (in our case $q=12$; see Table 1 ). For sectoral attribution of this total correction factor we need to derive the correction factors $f_{i}$ to the individual sectors $i \in[1, q]$ contributing to $f_{0}$.

We use two alternative methods for this purpose. The first method simply takes $f_{i}=f_{0}$ for all $i$, thus assuming that the partitioning of sectoral emissions in individual grid cells is correct in the prior inventory and all sectors contribute equally to the grid-level correction factor (Maasakkers et al., 2021; Lu et al., 2021; Zhang et al., 2021). These assumptions are reasonable when the sectors are spatially separated but may be a source of error when they spatially overlap. The second method (Shen et al., 2021) accounts for emissions from different sectors having different prior error standard deviation $\sigma_{i}$ and therefore contributing differently to $f_{0}$.
Following Shen et al. (2021), $f_{i}$ is then given by

$f_{i}=1-\frac{\eta \alpha_{i} \sigma_{i}^{2}\left(1-f_{0}\right)}{\sigma_{A}^{2}}$,

where $\alpha_{i}$ is the fraction of total emissions in the grid cell contributed by sector $i, \sigma_{A}$ is the prior error standard deviation for total emissions in the grid cell, and $\eta=\frac{\sigma_{A}^{2}}{\sum_{i=1}^{q} \alpha_{i}^{2} \sigma_{i}^{2}}$ is a normalization factor. For the prior error standard deviations $\sigma_{i}$ on the $0.5^{\circ} \times 0.625^{\circ}$ grid we use the scale-dependent adaptation by Maasakkers et al. (2016) of EPA sectoral national error estimates. This results in prior error standard deviations of $43 \%$ for rice, $66 \%$ for wastewater, $51 \%$ for landfills, $38 \%$ for livestock, $18 \%$ for coal, $30 \%$ for gas, and $87 \%$ for oil emissions. We further use $70 \%$ for wetlands (Bloom et al., 2017 ) and $100 \%$ for all other natural sources. These error estimates are solely used to infer $f_{i}$ values in Eq. (8) so that more uncertain emissions will contribute more to the correction. We use the second method in our base attribution of posterior estimates to emission sectors but will also use the results from the first method to contribute to error ranges in these sector-attributed posterior estimates.

We also need to aggregate posterior emission estimates nationally and by sector for comparison to the national emission inventories. Following Maasakkers et al. (2019), this is done by a transformation from the posterior full-dimension state vector $\hat{\boldsymbol{x}}$ to the reduced state vector $\hat{\boldsymbol{x}}_{\text {red }}$ (national emission for a given sector) with a summation matrix $\mathbf{W}$ :

$\hat{\boldsymbol{x}}_{\mathrm{red}}=\mathbf{W} \hat{\boldsymbol{x}}$.

The posterior error covariance and averaging kernel matrices for the reduced state vector are then given by

$\hat{\mathbf{S}}_{\mathrm{red}}=\mathbf{W} \hat{\mathbf{S}} \mathbf{W}^{T}$,

$\mathbf{A}_{\text {red }}=\mathbf{W A W}^{*}$,

where $\mathbf{W}^{*}=\mathbf{W}^{T}\left(\mathbf{W} \mathbf{W}^{T}\right)^{-1}$ (Calisesi et al., 2005). $\hat{\mathbf{S}}_{\mathrm{red}}$ enables us to determine whether national correction factors for individual sectors are affected by error correlations between sectors. A $_{\text {red }}$ enables us to determine the ability of the observing system to quantify national emissions from a particular sector independently from the prior estimate.

\section{Results and discussion}

\subsection{Base inversion compared to GOSAT-only and in-situ-only inversions}

Figure 3 a shows the gridded posterior correction factors from the base inversion averaged over 2010-2017, i.e., the multiplicative factors applied to the total prior emissions from Fig. 2, mapped on the $0.5^{\circ} \times 0.625^{\circ}$ model grid. Figure $3 b$ shows the corresponding averaging kernel sensitivities, indicating the dependence of the posterior solution on the prior 
Table 2. Settings for generation of the 33-member inversion ensemble ${ }^{\mathrm{a}}$.

\begin{tabular}{ll|ll}
\hline Observations & Regularization parameter $\gamma$ & \multicolumn{2}{c}{ Prior error standard deviation } \\
& & Emissions & Boundary conditions \\
\hline GOSAT + in situ & 1 & $50 \%($ lognormal) & $10 \mathrm{ppb}$ \\
GOSAT + in situ (long-term) $)^{\mathrm{c}}$ & 0.5 (GOSAT) & quadrature sum (lognormal) & $5 \mathrm{ppb}$ \\
GOSAT & & $50 \%$ (normal) & \\
In situ & & $95 \%($ normal) & \\
In situ (long-term) & & quadrature sum (normal) & \\
\hline
\end{tabular}

a Settings for the base inversion are in bold. The 33-member inversion ensemble uses the different combinations of settings to probe the effects of different choices in observations and in inversion parameters. The GOSAT + in situ inversion includes the following seven-member ensemble: (1) base inversion with $\gamma=1$ for in situ and GOSAT observations, $\sigma_{A}=50 \%$ (lognormal) for emissions, and $\sigma_{A}=10 \mathrm{ppb}$ for boundary conditions; (2) the same as (1) except that $\gamma=0.5$ for GOSAT observations; (3)-(6) the same as (1), except that $\sigma_{A}$ for emissions uses the other four options in the table; and (7) is the same as (1), except that $\sigma_{A}=5 \mathrm{ppb}$ for boundary conditions. Similarly, the GOSAT + in situ (long-term) and GOSAT inversions have seven ensemble members, respectively. The in situ and in situ (long-term) inversions have six ensemble members, respectively. This adds up to 33 inversion ensemble members. Sectoral attribution is done by two alternative methods (see text in Sect. 2.6), resulting in a total of 66 members.

${ }^{c}$ Including only long-term surface and tower sites with observations for all years of the 2010-2017 record.

$\mathrm{d}$ Adding the errors from individual sectors in quadrature following Maasakkers et al. (2021).

estimate (0: total dependence, 1 : no dependence). The number of independent pieces of information afforded by the observations (DOFS $=114)$ can be placed in the context of the 600 Gaussian state vector elements used to optimize the spatial distribution of emissions. We see that the observations provide considerable information to optimize methane emissions, but we also see that a finer resolution for the inversion would not be justified on the continental scale.

Figure 3c-f show the results from the GOSAT-only and insitu-only inversions, enabling us to compare the information contents and consistency of the two data sets. The GOSATonly inversion yields a DOFS of 68 , while the in-situ-only inversion yields a DOFS of 80 , even though there are $50 \%$ fewer in situ observations than GOSAT observations. This is because the sensitivities of surface observations to emissions are an order of magnitude higher than those of satellite observations (Cusworth et al., 2018). The GOSAT observations have the advantage of broader coverage. Thus, we find that the in situ observations dominate the information content of the base inversion over California, the upper Midwest, and Canada, whereas GOSAT dominates the information content in Mexico (where there are no in situ observations) and most of the western US. GOSAT and in situ observations contribute comparably in the south-central and eastern US, though with different weights in different locations. We conclude that GOSAT and in situ observations make comparable and complementary contributions to the optimization of methane emissions for North America.

We next examine the consistency in the information from GOSAT and in situ observations for correcting prior methane emissions. Inspection of the posterior correction factors from the GOSAT-only and in-situ-only inversions in Fig. 3 shows overall qualitative agreement. Figure 4 displays a more quantitative comparison of the posterior corrections by correlating the values for $0.5^{\circ} \times 0.625^{\circ}$ grid cells between the GOSATonly and in-situ-only inversions, selecting regions with relatively high averaging kernel sensitivities for both. We find overall good consistency between the two inversions (correlation coefficient $r=0.47$ for the ensemble of points, with $73 \%$ of grid cells showing corrections in the same direction). The reduced-major-axis regression slope is 0.62 , consistent with GOSAT providing overall less information. Both inversions find that methane emissions over the south-central US, the southeast US, the Great Plains, and Alberta are underestimated in the prior inventories. They also agree on downward corrections over central Canada and the upper Midwest where wetland emissions dominate. The largest inconsistency is over California where the two inversions show correction factors in the opposite direction for much of the state. This may reflect the coarse resolution of model $\mathrm{CO}_{2}$ used in the proxy GOSAT retrieval that leads to underestimation of $\mathrm{CO}_{2}$ (and hence methane) over the Los Angeles Basin (Turner et al., 2015; Maasakkers et al., 2021) and/or complex topography. Results from the base inversion tend toward either of the two inversions depending on which has the most information content.

We evaluated the ability of the base GOSAT + in situ inversion to fit the two observational data sets by comparing 2010-2017 GEOS-Chem simulations with posterior versus prior emissions and boundary conditions. Results are shown in Fig. 5. The posterior simulation reduces the model mean bias (MB) in surface and tower measurements from $-11 \mathrm{ppb}$ in the prior simulation to $-5 \mathrm{ppb}$, and it also narrows the root mean square error (RMSE) from 24 to $14 \mathrm{ppb}$. For GOSAT the improvement is less apparent from the continental-scale comparison statistics because the prior simulation already has a low mean bias (MB $=-0.5 \mathrm{ppb})$ and a small RMSE of $6.9 \mathrm{ppb}$. However, we see from Fig. 5 that the small mean bias reflects an offset between high bias in the western US and Canada and low bias in the central and eastern US. The inversion results in spatial whitening of this bias. Independent evaluation with the ground-based column observations from the Total Carbon Column Observing Network (TCCON) (Wunch et al., 2011) further shows that the 

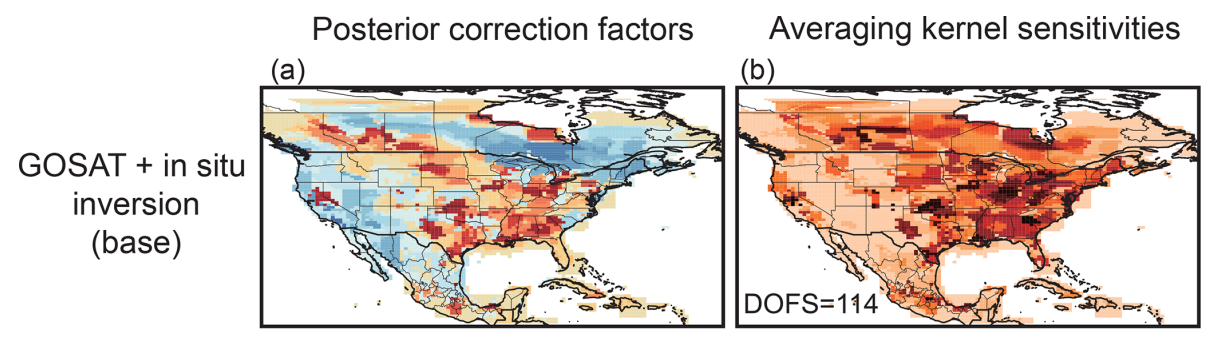

(c)

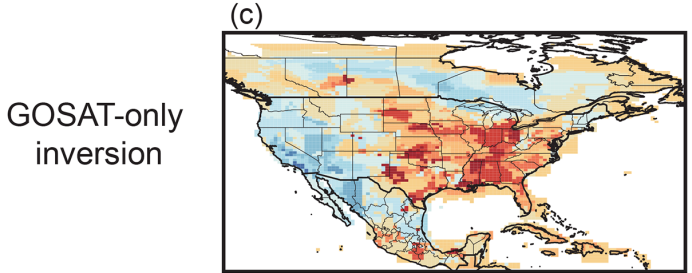

(d)
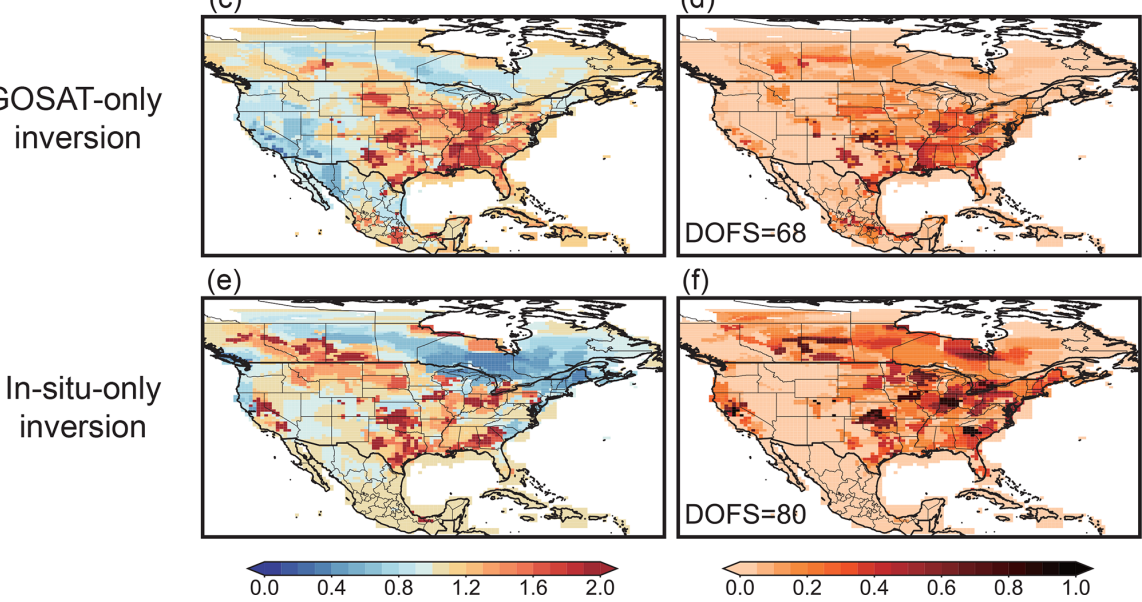

(f)

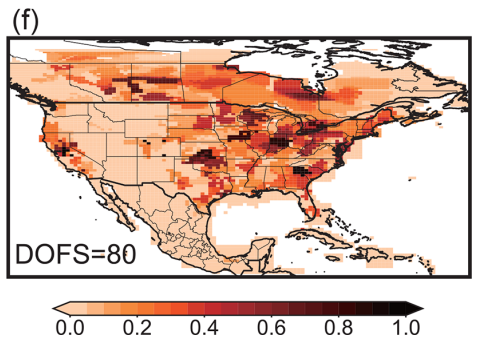

Figure 3. Optimization of mean 2010-2017 methane emissions over North America. Results are from the base inversion using both GOSAT and GLOBALVIEWplus in situ observations, the GOSAT-only inversion, and the in-situ-only inversion. The left panels show the posterior correction factors, i.e., the multiplicative factors applied to the total prior emissions in Fig. 2, and the right panels show the averaging kernel sensitivities (diagonal elements of the averaging kernel matrix). The degrees of freedom for signal (DOFS, defined as the trace of the averaging kernel matrix) are shown in the inset.

mean model bias at five sites in CONUS decreases from 5.2$14.0 \mathrm{ppbv}$ in the prior simulation to $1.0-13.5 \mathrm{ppbv}$ in the posterior simulation.

\subsection{Optimized 2010-2017 anthropogenic methane emissions for CONUS, Canada, and Mexico}

Table 1 (a-c) summarizes our inversion results for national 2010-2017 methane emissions by sector in CONUS, Canada, and Mexico. Our best posterior estimates of total anthropogenic + natural emissions from the base inversion are $46.3(40.2-48.4) \mathrm{Tga}^{-1}$ for CONUS, 16.2 (13.517.4) $\mathrm{Tg} \mathrm{a}^{-1}$ for Canada, and 6.8 (5.4-6.9) $\mathrm{Tg} \mathrm{a}^{-1}$ for Mexico. The ranges given in parentheses are from the 33 inversion ensemble members (Table 2). Averaging kernel sensitivities for these total national emissions (the diagonal elements in $\mathbf{A}_{\text {red }}$, Sect. 2.6) are 0.72 for CONUS, 0.60 for Canada, and 0.40 for Mexico, indicating that the GOSAT + in situ observation system informs $72 \%$ of total methane emissions in CONUS, $60 \%$ in Canada, and $40 \%$ in Mexico, with the remainder of the posterior emissions anchored to the prior estimate. The lower information content for Mexico is due to the lack of in situ observations.

We partition these national totals into different sectors as described in Sect. 2.6 and use the posterior error covari- ance matrix (Eq. 10) to evaluate the ability of the inversion to separate between sectors. This is shown in Fig. 6 as the posterior error correlation matrix, displaying the error correlation coefficients $(r)$ in the inversion results for all sector pairs. Error correlation coefficients are generally lower than 0.2 for CONUS, indicating successful separation, except for small sources (termites, seeps, other anthropogenic). The same holds for Canada except for error correlation between landfills and wastewater treatment, which are both associated with urban areas. Anthropogenic emissions in Canada are well separated from the large wetland emissions. Error correlations are higher in Mexico because emissions from different sectors tend to be concentrated in Mexico City and the eastern part of the country (Scarpelli et al., 2020), but even there the error correlation coefficients are generally less than 0.4 . Optimization of the oil and gas sector is well separated from the other sectors in all three countries, and separation between oil and gas is also successful because the two sectors have very different spatial distributions in the gridded inventories (Fig. 2). However, there is some ambiguity for the production subsectors because wells often produce both oil and gas (Maasakkers et al., 2016), and for this reason some studies prefer to refer to oil and gas emissions as a combined sector (Alvarez et al., 2018). Separating oil and gas emis- 


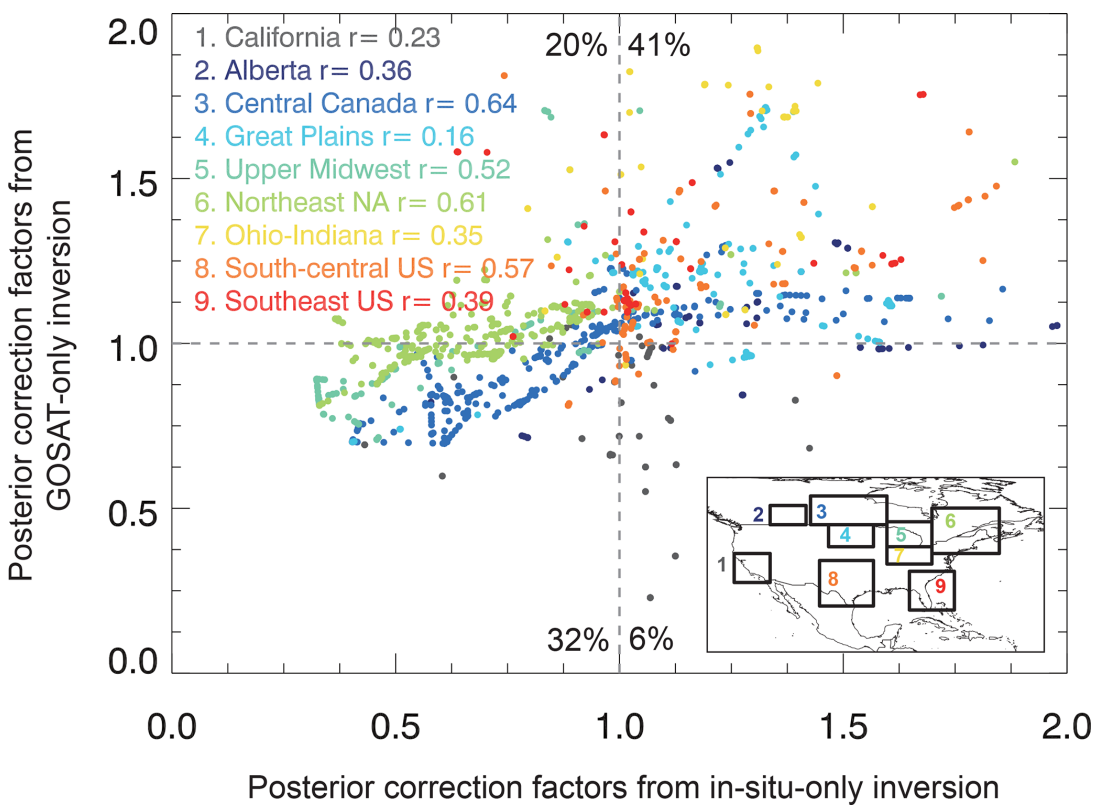

Figure 4. Comparison of posterior correction factors to prior methane emissions on the $0.5^{\circ} \times 0.625^{\circ}$ grid between GOSAT-only and insitu-only inversions. The comparisons are for nine regions with relatively high averaging kernel sensitivities for both inversions. Each point represents the posterior correction factors from both inversions in a $0.5^{\circ} \times 0.625^{\circ}$ grid cell (Fig. 3). Correlation coefficients for each of the nine regions are shown in the inset. Percentiles in each quadrant show the fraction of the total points in that quadrant.

sions is useful for our purpose because such separation is required under UNFCCC reporting, but the reader should be aware that this separation is done on the basis of the spatial distributions of emissions in Fig. 2.

We find that anthropogenic methane emissions for all three countries are larger in our inversion results than in the national inventories submitted to the UNFCCC. Our best estimate of the mean 2010-2017 anthropogenic methane emission for CONUS is $36.9(32.5-37.8) \mathrm{Tga}^{-1}$, which is $30 \%$ higher than the $28.7 \mathrm{Tg} \mathrm{a}^{-1}$ in the 2016 version of the EPA GHGI used as a prior estimate (EPA, 2016) and $42 \%$ higher than the mean $26.0 \mathrm{Tg} \mathrm{a}^{-1}$ for 2010-2017 in the most recent version of the GHGI (EPA, 2021). Maasakkers et al. (2021) previously obtained a mean 2010-2015 CONUS anthropogenic emission of $30.6(29.4-31.3) \mathrm{Tg} \mathrm{a}^{-1}$ by inversion of GOSAT data using the same prior anthropogenic estimate as ours but a much higher prior estimate for CONUS wetlands $\left(15.7 \mathrm{Tg} \mathrm{a}^{-1}\right)$. The need to decrease the wetlands source in their inversion (to a posterior estimate of $11.8 \mathrm{Tg} \mathrm{a}^{-1}$ ), as well as their reliance on GOSAT observations only, may have dampened their ability to quantify anthropogenic emissions.

Our best estimate of the mean 2010-2017 anthropogenic methane emission for Canada is $5.3(3.6-5.7) \mathrm{Tg} \mathrm{a}^{-1}$, which is $43 \%$ higher than the $3.7 \mathrm{Tg} \mathrm{a}^{-1}$ in the ECCC NIR (2020 version) used as a prior estimate and $33 \%$ higher than the 4.0 $\mathrm{Tg} \mathrm{a}^{-1}$ for $2010-2017$ reported in the most recent version of the ECCC NIR (ECCC, 2021). Baray et al. (2021) previously obtained a mean 2010-2015 anthropogenic emission of $6.1 \mathrm{Tg} \mathrm{a}^{-1}$ for Canada by inversion of data from GOSAT and ECCC surface sites.

Our best estimate of the mean 2010-2017 anthropogenic methane emission for Mexico is 6.0 (4.7-6.1) $\mathrm{Tg} \mathrm{a}^{-1}$, which is $20 \%$ higher than the $5.0 \mathrm{Tg} \mathrm{a}^{-1}$ in Mexico's national inventory (INECC and SEMARNAT, 2018) used as a prior estimate. Shen et al. (2021) similarly found higher emissions than the national inventory in their inversion of TROPOMI satellite methane data for eastern Mexico.

Figure 7 displays the data from Table 1a-c for the national posterior emission estimates from different sectors in comparison with the EPA (US), ECCC (Canada), and INECC (Mexico) national inventories used as prior estimates. We find that emissions from all major sectors except coal and wastewater are lower in the national inventories than our inversion results, with the largest underestimates for fugitive emissions from the oil sector. The total CONUS oil and gas emissions in our inversion are 4.6 and $9.9 \mathrm{Tg} \mathrm{a}^{-1}$, respectively, which is $109 \%$ and $45 \%$ higher than the EPA (2016) inventory used here as a prior estimate and $177 \%$ and $65 \%$ higher than the most recent EPA (EPA, 2021) inventory for the 2010-2017 mean. The EPA inventory reports an uncertainty of $-24 \%$ to $+29 \%$ for oil and $-15 \%$ to $+14 \%$ for natural gas emissions (EPA, 2021). Our estimates are also higher than those in Maasakkers et al. (2021), which are 3.6 and $8.0 \mathrm{Tg} \mathrm{a}^{-1}$, respectively, for oil and gas emissions in 2010-2015. They are consistent with the Alvarez et al. (2018) estimates for total CONUS oil and gas emissions of $13(11-15) \mathrm{Tg} \mathrm{a}^{-1}$ in 2015 based on field measure- 
Mean 2010-2017 difference between GEOS-Chem and observations
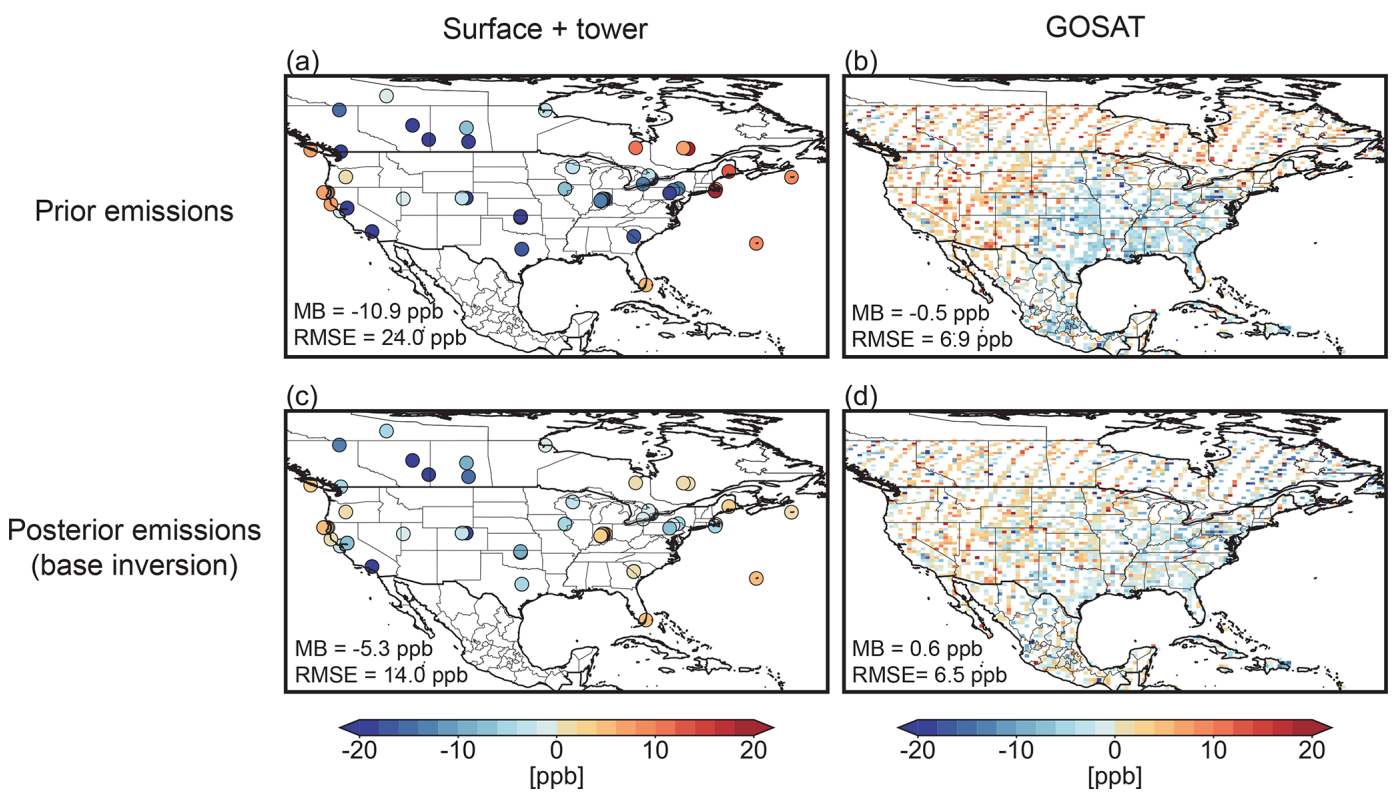

(d)

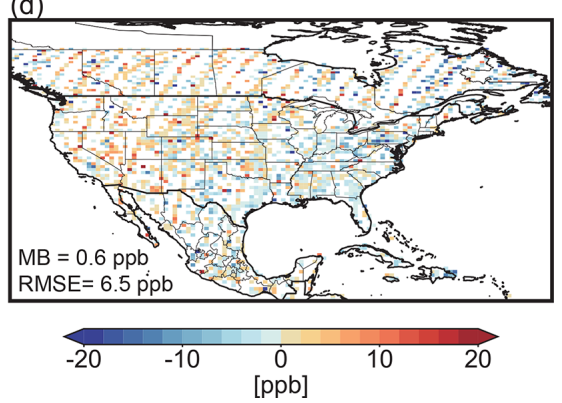

Figure 5. Ability of the base inversion to fit the in situ (surface and tower) and GOSAT observations for 2010-2017. The figure shows the mean differences between GEOS-Chem simulations and the observations using either prior or posterior methane emissions. Mean bias (MB) and root mean square error (RMSE) are shown in the inset, calculated from the temporally averaged differences for each in situ site or GOSAT grid cell.

ments within oil and gas basins, scaled up to derive a national value.

We mentioned previously that the lower estimates in Maasakkers et al. (2021) could reflect their use of GOSAT observations only, the difference in time frame, and their high prior estimate for wetlands, but another factor is their assumption of normal distributions for prior emission error standard deviations. We find from our inversion ensemble that assuming a lognormal distribution (as in our base inversion) rather than a normal distribution increases the resulting posterior oil and gas emissions by 0.8 and $0.9 \mathrm{Tg} \mathrm{a}^{-1}$, respectively. This is because the lognormal distribution does much better at capturing the heavy tail of the emission probability density functions for oil and gas production (Zavala-Araiza et al., 2015; Frankenberg et al., 2016; Alvarez et al., 2018). Adding the in situ observations to the GOSAT-only inversion further increases the posterior oil and gas emissions by 0.2 and $0.3 \mathrm{Tg} \mathrm{a}^{-1}$, respectively. The assumption of larger uncertainty of oil than gas emissions in Eq. (8) furthermore attributes larger upward corrections to oil emissions. Thus, our base inversion yields the high end of the estimated range from the inversion ensemble (Table 1a) but still represents our best estimate.

Our inversion increases the oil emissions over Canada by more than a factor of 2 to $1.8 \mathrm{Tg} \mathrm{a}^{-1}$ compared to the ECCC inventory. The total posterior oil and gas emissions for Canada are $2.9(1.6-3.3) \mathrm{Tg} \mathrm{a}^{-1}$. This is in good agreement with a recent inversion study $\left(3.0 \mathrm{Tg} \mathrm{a}^{-1}\right)$ based on 2010
2017 surface methane measurements in western Canada (Chan et al., 2020). Most of the information for Canada in our base inversion indeed comes from the in situ measurements (Fig. 3), which are relatively dense in Canada (Fig. 1), and considering that GOSAT observations at high latitudes are relatively sparse and seasonally limited (Lu et al., 2021). Maasakkers et al. (2021) previously found little information for Canadian anthropogenic emissions in their GOSAT-only inversion, although that was further complicated by their large overestimate of prior wetland emissions that dominate total emissions in Canada.

We further compared our oil and gas inversion results for CONUS, Canada, and Mexico to the TRACE bottom-up inventory aggregating data from individual assets up to the country level (Climate TRACE, 2021). This inventory uses life-cycle assessment emissions models for production, processing, refining, and shipping (Gordon et al., 2015; Masnadi et al., 2018; Gordon and Reuland, 2021). The TRACE oil and gas total emission estimates for CONUS $\left(9.6 \mathrm{Tg} \mathrm{a}^{-1}\right)$, Canada $\left(1.8 \mathrm{Tg} \mathrm{a}^{-1}\right)$, and Mexico $\left(0.8 \mathrm{Tg} \mathrm{a}^{-1}\right)$ are similar to the prior estimates from the EPA, ECCC, and INECC, respectively (Table 1), and correspondingly lower than our best posterior estimates of $14.5 \mathrm{Tg} \mathrm{a}^{-1}$ for CONUS, $3.2 \mathrm{Tg} \mathrm{a}^{-1}$ for Canada, and $1.3 \mathrm{Tg} \mathrm{a}^{-1}$ for Mexico. The bottom-up oil and gas modeling in TRACE assesses routine methane emissions from normal operations, assuming normal fugitive emissions. Recent flyover work, however, shows that methane 


\section{Posterior error correlations between sectors}

(a) CONUS

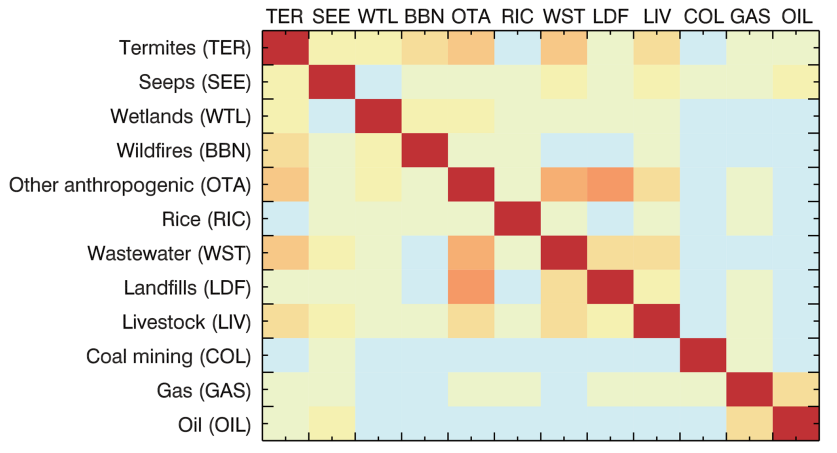

(b) Canada

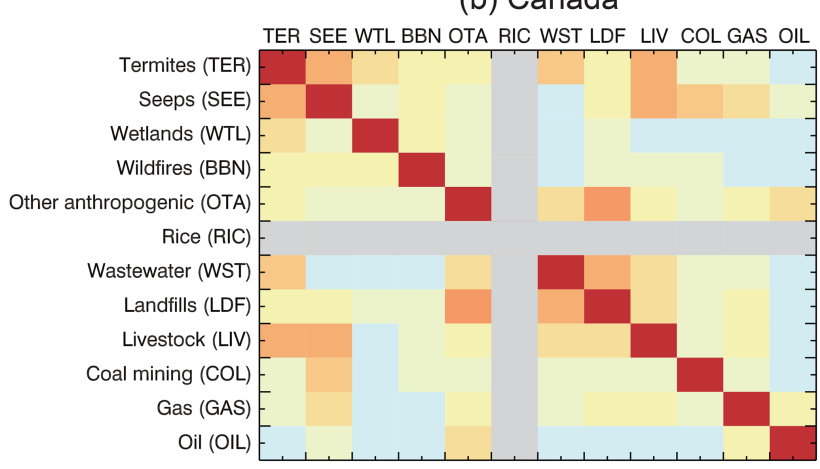

(c) Mexico

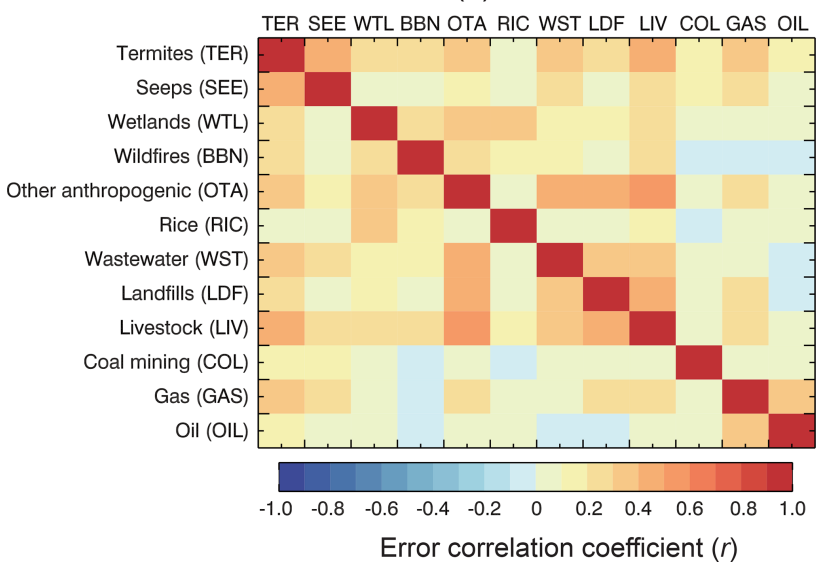

Figure 6. Posterior error correlation coefficients $(r)$ between sectoral methane emissions in the contiguous US (CONUS), Canada, and Mexico+ using the sector-aggregated error covariance matrix as described in Sect. 2.6. Error correlation coefficients indicate the ability of the inversion to separate emissions between sectors $(0$ : perfectly, \pm 1 : not at all). Results are from the base inversion for the year 2015. Results for other years show similar patterns.

emissions are highly intermittent (Cusworth, et. al., 2021), and this is not well captured in bottom-up estimates.

Figure 8 shows the spatial distributions of posterior correction to the gridded version of national inventories for the oil, gas, livestock, and landfill sectors. We find large upward
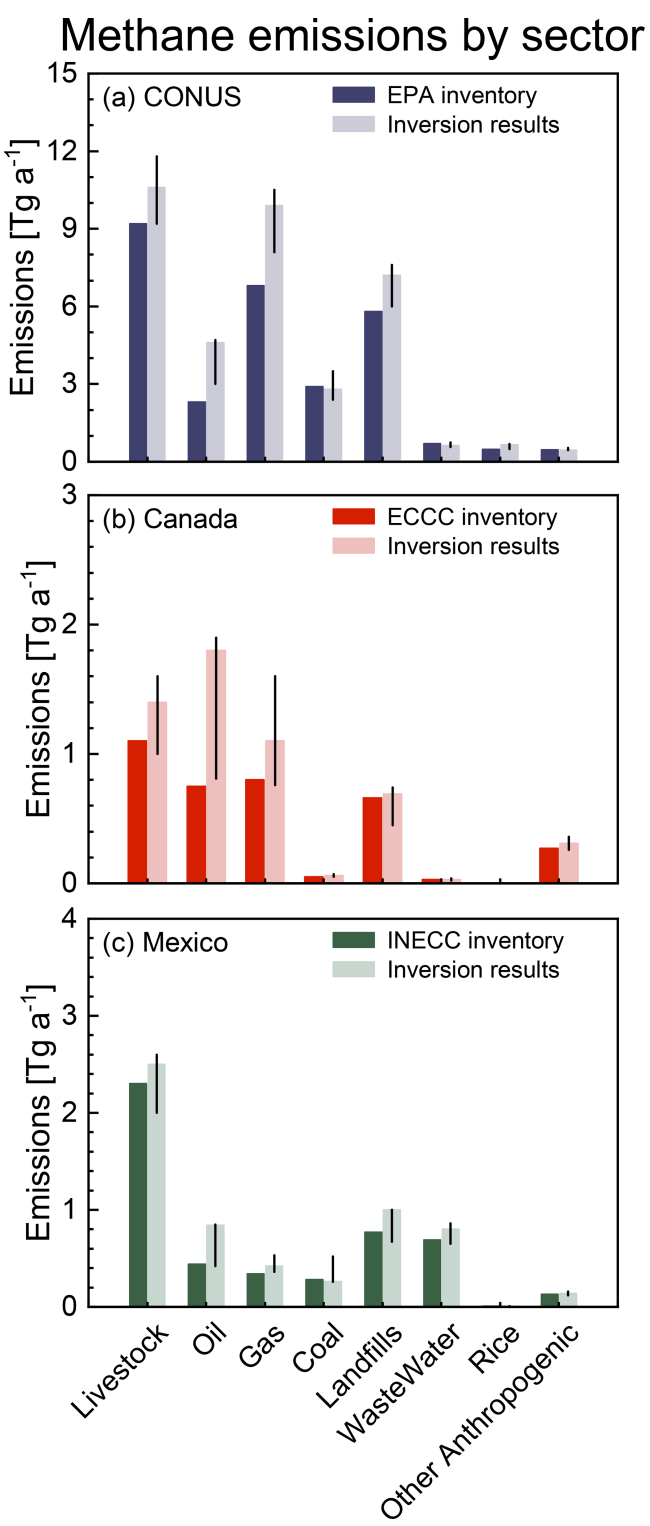

Figure 7. Mean 2010-2017 anthropogenic methane emissions by source sectors for the contiguous US (CONUS), Canada, and Mexico, displaying values and ranges from the corresponding Table 1ac. The official UNFCCC-reported national inventories for the US (EPA), Canada (ECCC), and Mexico (INECC) are used as prior estimates for the inversion. Inversion results are from the base inversion of GOSAT + in situ observations, and the ranges are for the ensemble of 66 sensitivity inversions (Table 2) and sectoral attribution methods (Sect. 2.6).

corrections for the major oil and gas production basins in the US including the Permian, Barnett Shale, Eagle Ford, Bakken Shale, Marcellus Shale, and Anadarko basins, consistent with previous reports based on field measurements and satellite observations (Miller et al., 2013; Karion et al., 2015; Peischl et al., 2015; Lyon et al., 2015; Ren et al., 2019; Robertson et al., 2020; Zhang et al., 2020). Upward correc- 
tions in Canada are concentrated over the oil and gas production regions of Alberta and Saskatchewan, again consistent with previous studies (Johnson et al., 2017; Baray et al., 2018; Chan et al., 2020). For Mexico the upward correction is concentrated in the onshore Sureste Basin, which is the largest oil field in the country, but with a downward correction for offshore operations. This is consistent with aircraft and TROPOMI satellite observations, which attributed the low offshore emissions to piping of the gas onshore followed by inefficient flaring (Zavala-Araiza et al., 2021; Shen et al., 2021). In addition, methane released to the ocean could be oxidized to $\mathrm{CO}_{2}$ in the oxic water and hence not reach the atmosphere.

The spatial distribution of posterior corrections to livestock emissions indicates that the national inventories are too low for most regions, although there are exceptions, in particular in the western US (Fig. 8). The highest emissions in the gridded version of the EPA (2016) GHGI are for the upper Midwest, and our inversion results suggest that these are too low, possibly reflecting higher-emitting manure management systems from confined animal feeding operations than included in the GHGI calculations (Sheng et al., 2018a). Yu et al. (2021) also found from an aircraft-based inversion that livestock emissions from the EPA inventory over the US corn belt and upper Midwest region are underestimated by $25 \%$ during summer and winter.

Our inversion finds CONUS methane emissions from landfills of $7.2(6.0-7.6) \mathrm{Tg} \mathrm{a}^{-1}$, which is $24 \%$ higher than the prior EPA (2016) estimate of $5.8 \mathrm{Tg} \mathrm{a}^{-1}$. The most recent EPA (2021) inventory gives $4.5 \mathrm{Tg} \mathrm{a}^{-1}$ for landfill emissions with an uncertainty of $\pm 22 \%$. The organic decay rate and methane production potential used in the GHGI calculation may be too low (Wang et al., 2013; Sun et al., 2019).

\subsection{The 2010-2017 trends in anthropogenic methane emissions}

Our inversion optimizes emissions for individual years in 2010-2017, allowing investigation of emission trends. Figure 9 shows the 2010-2017 time series of total anthropogenic methane emissions from CONUS, Canada, and Mexico, as well as the contributions from the dominant sectors (oil, gas, coal, livestock, and landfills). We include no trend in the prior estimates so that the trends in Fig. 9 are solely driven by the observations. Table 3 gives the corresponding 20102017 linear trends in emissions inferred from ordinary linear regression and compares to the trends reported in the most recent national inventories for the US (EPA, 2021) and Canada (ECCC, 2021). Mexico only reports emissions up to 2015.

Our inversion shows that over the time frame of 2010 to 2017, total anthropogenic methane emissions in CONUS peaked in 2014 and then decreased, resulting in no net trend for the 2010-2017 period $\left(+0.1(-0.1\right.$ to +0.3$\left.) \% \mathrm{a}^{-1}\right)$. The increasing trend for $2010-2015$ is $+0.9(+0.4$ to $+1.8) \% \mathrm{a}^{-1}$, which is higher than $+0.4 \% \mathrm{a}^{-1}$ in the
GOSAT-only inversion by Maasakkers et al. (2021) and more consistent with the $0.7 \pm 0.3 \% \mathrm{a}^{-1}$ for $2006-2015$ estimated by Lan et al. (2019). Inspection of CONUS trends for different emission sectors in the base inversion indicates that the 2014 maximum largely reflects opposite trends between oil and landfill emissions, which increased by +2.9 $(+1.0$ to +2.9$) \% \mathrm{a}^{-1}$ and $+1.7(+1.0$ to +1.8$) \% \mathrm{a}^{-1}$, respectively, over the 2010-2017 period, and gas emissions, which decreased by $1.8 \% \mathrm{a}^{-1}$ over the 2010-2017 period, with livestock and coal emissions showing no significant trend (Fig. 9). In contrast, the most recent EPA GHGI inventory reports a steady decreasing trend of $-0.8 \% \mathrm{a}^{-1}$ in US anthropogenic methane emissions over the 20102017 period mostly driven by coal $\left(-5.4 \% \mathrm{a}^{-1}\right)$ and landfills $\left(-1.6 \% \mathrm{a}^{-1}\right)$ (EPA, 2021). The decrease for gas is more pronounced in our inversion than in the EPA inventory $\left(-0.4 \% \mathrm{a}^{-1}\right)$. The EPA inventory reports no significant trend for oil emissions and attributes the decrease in gas emissions to gas exploration ( $80 \%$ decrease from 2010 level) and distribution (12\% decrease from 2010 level), with flat emissions from gas production. However, both oil production and natural gas production have increased significantly over the period (https://www.eia.gov/, last access: 31 July 2021). More work is required to understand the discrepancies in oil and gas trend estimates between the inversion and EPA reports. We cannot exclude the possibility that oil and gas emissions are not adequately separated in the EPA inventory and/or the inversion at this stage.

Figure 10 shows the spatial distributions of the linear regression fits to the 2010-2017 trends for the major anthropogenic sectors, i.e., the equivalent linear trends over the period. We find that the oil increases are mostly driven by major basins in the south-central US including the Permian and Eagle Ford basins. The gas decreases are mostly driven by fields in the western US (Niobrara) and southeastern US (Haynesville). Livestock emissions show variable regional patterns of increase and decrease that could reflect variations in animal populations. The increase in Iowa is consistent with a previous study of GOSAT trends by Sheng et al. (2018a), who attributed it to an increase in the number of swine (Iowa Department of Natural Resources, 2017). Landfills also show variable patterns of increase and decrease.

The ECCC reports no significant trends of Canadian anthropogenic methane emissions over 2010-2017 but notes some decreases in oil emissions, in particular after 2014 (ECCC, 2021). Here we find a decreasing trend in Canadian anthropogenic emissions of -2.3 ( -2.5 to -1.6$) \% \mathrm{a}^{-1}$ from the inversion, mainly driven by gas $(-3.8(-3.9$ to $\left.-1.7) \% \mathrm{a}^{-1}\right)$ and oil $\left(-1.7(-2.0\right.$ to -0.4$\left.) \% \mathrm{a}^{-1}\right)$. This may reflect reductions in livestock and oil and gas emissions over this period (ECCC, 2020b) as well as the ongoing regulation of methane released from the oil and gas sectors following the Pan-Canadian Framework on Clean Growth and Climate Change, which aims to reduce methane emissions by $40 \%-45 \%$ by 2025 relative to the 2012 level (ECCC, 


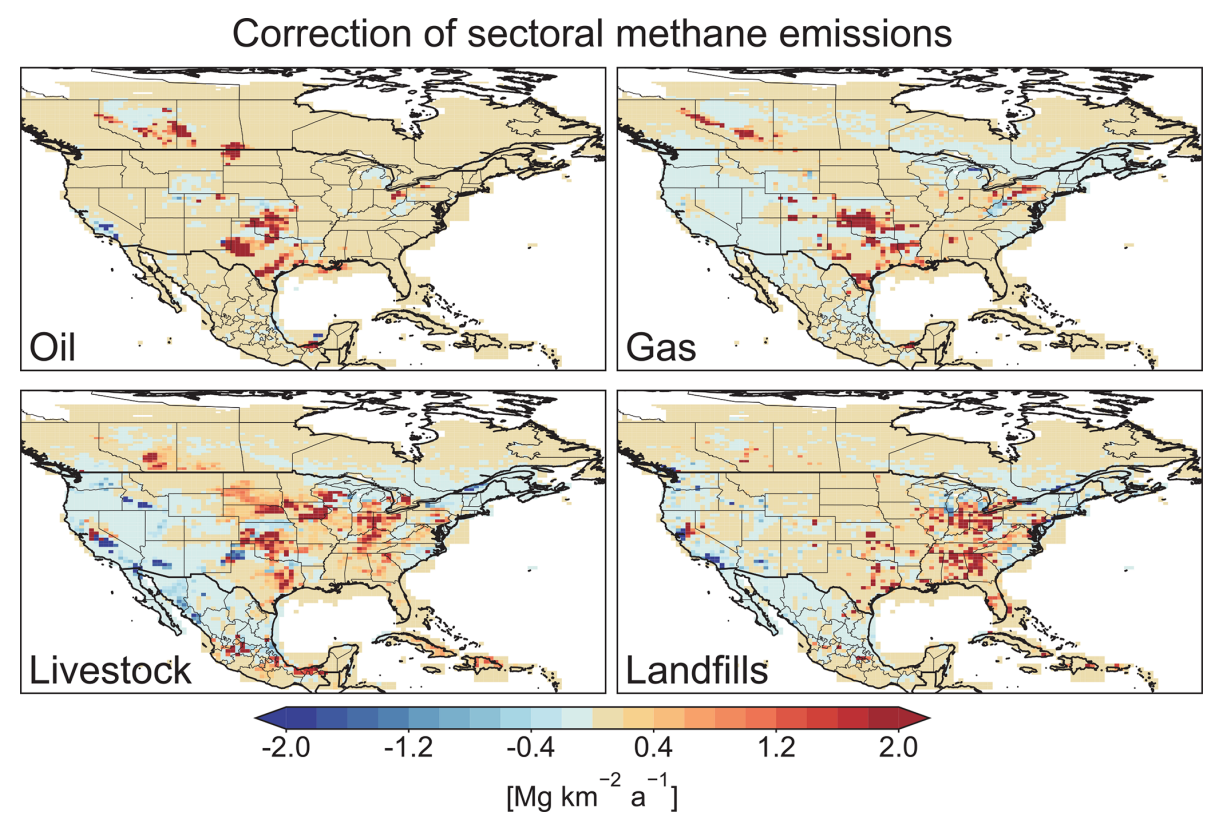

Figure 8. Posterior correction for mean 2010-2017 methane emissions from the oil, gas, livestock, and landfill sectors as given by the base inversion. The correction factors for anthropogenic emissions are relative to the national emission inventories used as prior estimates (EPA GHGI for the US, ECCC NIR for Canada, INECC for Mexico).

Table 3. The 2010-2017 trends in methane anthropogenic emissions $\left(\% \mathrm{yr}^{-1}\right)^{\mathrm{a}}$.

\begin{tabular}{lrr}
\hline & Inversion ensemble $^{\mathrm{b}}$ & National inventories $^{\mathrm{c}}$ \\
\hline CONUS & & \\
\hline Total anthropogenic & $+0.10(-0.11$ to +0.34$)$ & $-0.8^{*}$ \\
\hline Livestock & $-0.25(-0.61$ to +0.09$)$ & +0.5 \\
Oil & $+2.9^{*}(+1.0$ to +2.9$)$ & -0.4 \\
Natural gas & $-1.8^{*}(-1.8$ to -0.48$)$ & $-0.4^{*}$ \\
Coal mining & $-1.0(-1.9$ to -0.04$)$ & $-5.4^{*}$ \\
Landfills & $+1.7^{*}(+1.0$ to +1.8$)$ & $-1.6^{*}$ \\
\hline Canada & & -0.3 \\
\hline Total anthropogenic & $-2.3(-2.5$ to -1.6$)$ & -0.3 \\
Livestock & $-2.2(-2.7$ to -1.5$)$ & -1.2 \\
Oil & $-1.7(-2.0$ to -0.42$)$ & -0.1 \\
Natural gas & $-3.8(-3.9$ to -1.7$)$ & $-0.4^{*}$ \\
Landfills & $-2.3(-3.9$ to -1.7$)$ & \\
\hline Mexico & & $\mathrm{NA}$ \\
\hline Total anthropogenic & $-3.3(-3.4$ to -1.7$)$ & $\mathrm{NA}$ \\
Oil & $-11.6^{*}(-15.0$ to -3.5$)$ & $\mathrm{NA}$ \\
Natural gas & $-3.1(-6.1$ to -1.0$)$ & \\
\hline
\end{tabular}

${ }^{\text {a}}$ From ordinary linear regression of emissions in individual years, reported in $\% \mathrm{a}^{-1}$ relative to the 2010-2017 mean. Figure 9 shows the time series for the base inversion. Trends marked with * are significant with a $p$ value $<0.1$.

${ }^{\mathrm{b}}$ Trends from the base inversion, with the range of trends from the inversion ensemble members in parentheses.

${ }^{\mathrm{c}}$ From national inventory emissions in individual years reported by the Environmental Protection Agency (EPA, 2021) and Environment and Climate Change Canada (ECCC, 2021). INECC in Mexico only reports emissions up to 2015 , hence the entries marked not available (NA). 
Posterior anthropogenic emissions $\left[\mathrm{Tg} \mathrm{a}^{-1}\right]$

(a) CONUS

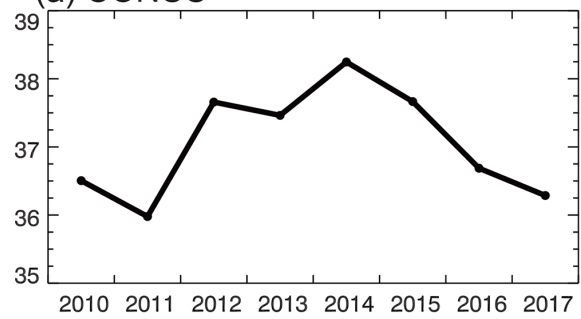

(c) Canada

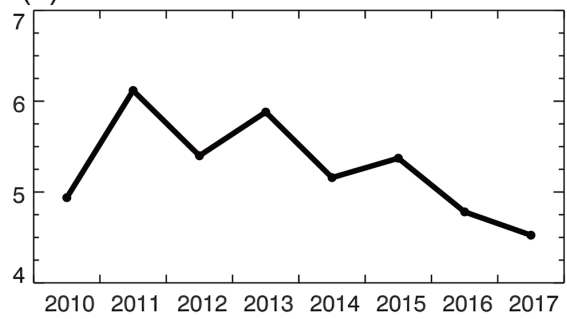

(e) Mexico

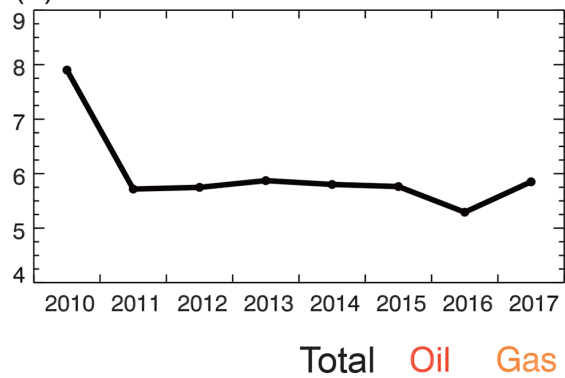

Emission changes relative to 2010 $\left[\operatorname{Tg~a~}^{-1}\right]$

(b) CONUS

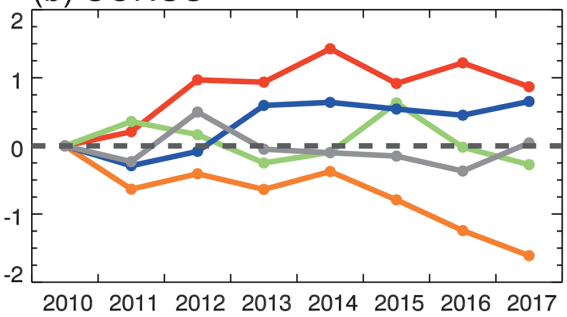

(d) Canada

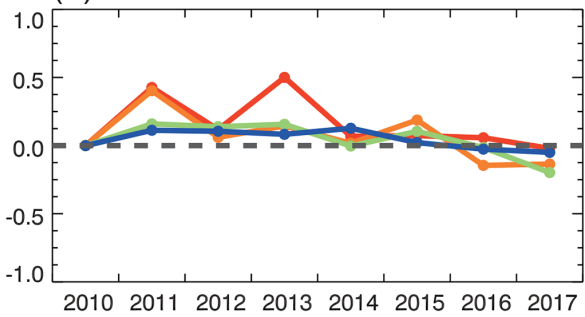

(f) Mexico

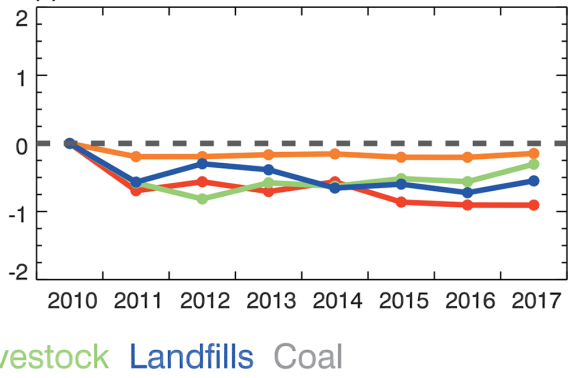

Figure 9. The 2010-2017 trends in anthropogenic methane emissions in CONUS, Canada, and Mexico as inferred from the base inversion. The left panels show the total national anthropogenic methane emissions, and the right panels show changes relative to 2010 for major sectors.

2017). The inversion also suggests a decreasing trend in total Mexican anthropogenic methane emissions by $-3.3(-3.4$ to -1.7$) \% \mathrm{a}^{-1}$, but this is mainly driven by a decrease from 2010 to 2011, in particular for offshore Sureste oil emissions, and is consistent with the increasing utilization of associated gas (Zhang et al., 2019).

\subsection{The 2010-2017 wetland methane emissions and trends}

Our inversion shows a strong ability to optimize wetland emissions over CONUS and Canada (averaging kernel sensitivity of 0.57). Wetland emissions in Mexico are much smaller and are not efficiently optimized by the inversion, as shown in Table 1c. Posterior wetland emissions are 8.4 (6.4-10.6) $\mathrm{Tg} \mathrm{a}^{-1}$ for CONUS and $9.9(7.8-12.0) \mathrm{Tg} \mathrm{a}^{-1}$ for Canada compared to 7.5 and $12.0 \mathrm{Tga}^{-1}$ in the prior estimate from the WetCHARTs v1.3.1 high-performance subset for North America (Ma et al., 2021). There are larger regional upward (southeast US) and downward (upper Midwest) cor- rections even with this high-performance subset, as shown in Fig. 11, pointing to major gaps in our understanding.

Figures 11 and 12 show the 2010-2017 trends of wetland emissions for CONUS and Canada. We find a significant increase of $+2.6(+1.7$ to +3.8$) \% \mathrm{a}^{-1}$ in wetland methane emissions over CONUS in 2010-2017, in particular after 2014, and this is consistent with but higher than the WetCHARTs trend estimates of $1.3 \% \mathrm{a}^{-1}$ (not used in the inversion). The trends over CONUS are mostly driven by increases in the southeast US (Fig. 11b). Fluctuations in emissions for temperate and boreal wetlands are mostly modulated by temperature, snowmelt, precipitation, and drought events (Watts et al., 2014). We find a significant correlation of 0.89 between the CONUS wetland emissions and annual precipitation in the CONUS wetland regions and a strong 2010-2017 increase in precipitation that may drive the wetland trends (Fig. 12c). Wetland emissions over Canada do not show significant trends in the inversion. The 2016 peak is consistent with WetCHARTs and may be explained by high precipitation (Fig. 12d). 
Methane emission trends, 2010-2017
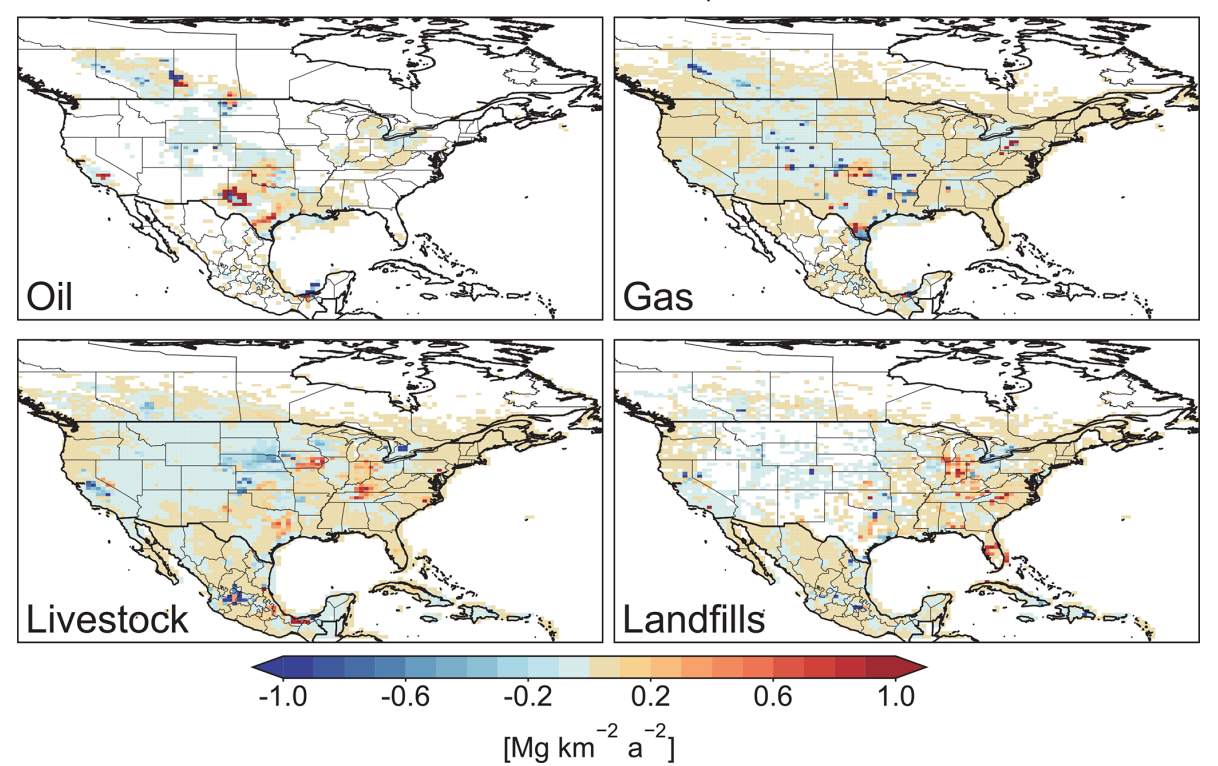

Figure 10. The 2010-2017 linear trends in emissions from major anthropogenic sectors on the $0.5^{\circ} \times 0.625^{\circ}$ grid as inferred from the base inversion. The linear trends are fitted by linear regression to the inversion results for individual years. Areas in white have no emissions from the corresponding sector.

Correction of wetland emissions

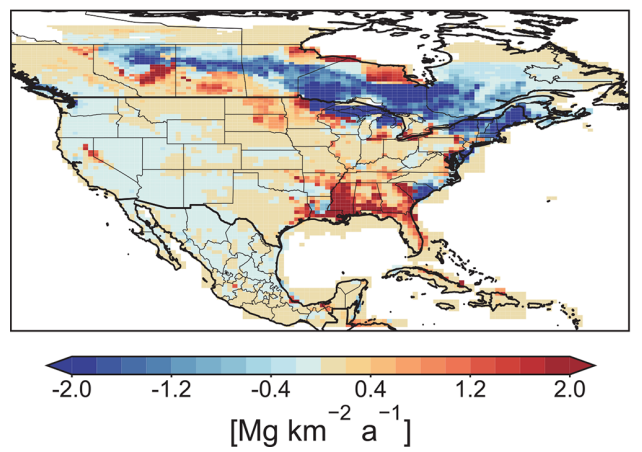

Wetland emission trends, 2010-2017

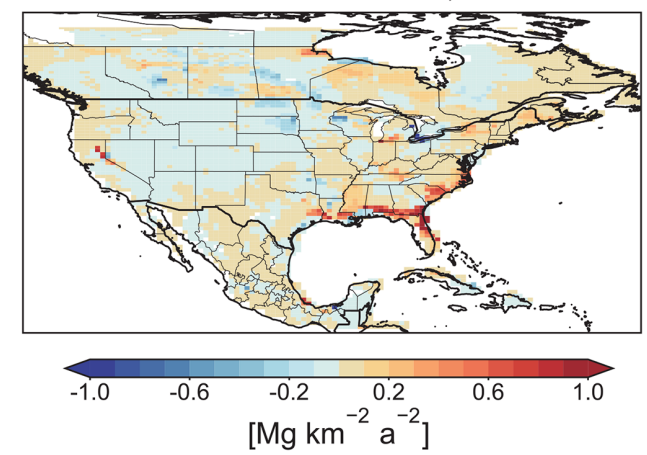

Figure 11. Posterior correction and linear trends for 2010-2017 wetland emissions in North America. The posterior correction factors are relative to the 2010-2017 mean of the high-performance subset of the WetCHARTs inventory ensemble (Ma et al., 2021). The linear trends are from ordinary linear regression to base inversion results for individual years.

\section{Conclusions}

We estimated mean methane emissions and trends for 2010 2017 in the contiguous United States (CONUS), Canada, and Mexico by inversion of in situ (GLOBALVIEWplus $\mathrm{CH}_{4}$ ObsPack) and satellite (GOSAT) atmospheric methane observations. Our inversion used gridded versions of the national anthropogenic emission inventories reported to the UNFCCC by EPA (CONUS), ECCC (Canada), and INECC (Mexico) as prior estimates. It optimized a 600-member Gaussian mixture model (GMM) of emissions for individual years at up to $0.5^{\circ} \times 0.625^{\circ}$ resolution using lognormal prior error statistics on emissions to account for the heavy tail in the probability distribution. The inversion solved for the minimum of the Bayesian cost function with lognormal prior statistics analytically, thus enabling a large inversion ensemble to test the sensitivity of results to a range of assumptions and providing closed-form expressions of posterior error covariance and information content. We find that GOSAT and in situ observations make comparable and complementary contributions to the optimization of methane emissions for North America and that they show overall consistent corrections to prior methane emissions.

We estimate from our base inversion a mean 2010-2017 methane emission for CONUS of 46.3 (40.2-48.4 ensemble range) $\mathrm{Tg} \mathrm{a}^{-1}, 36.9(32.5-37.8) \mathrm{Tg} \mathrm{a}^{-1}$ of which is anthro- 


\section{Wetland emissions $\left[\mathrm{Tg} \mathrm{a}{ }^{-1}\right]$}

\section{(a) CONUS}

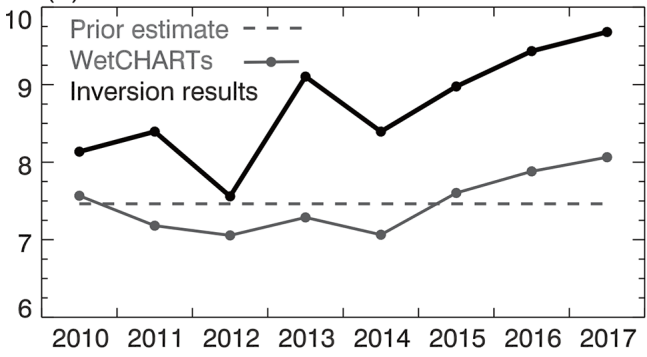

(c) Canada

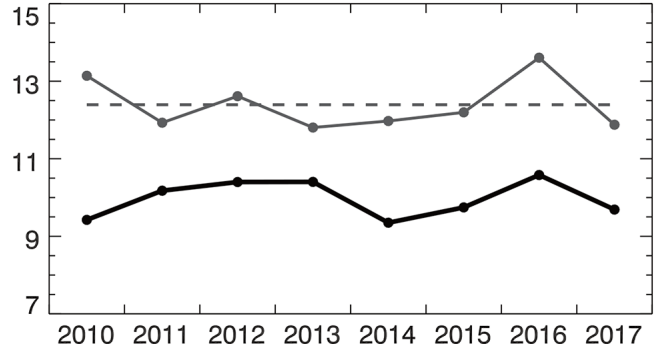

Wetland-weighted annual precipitation $\left[\mathrm{mm} \mathrm{a}^{-1}\right]$ (b) CONUS

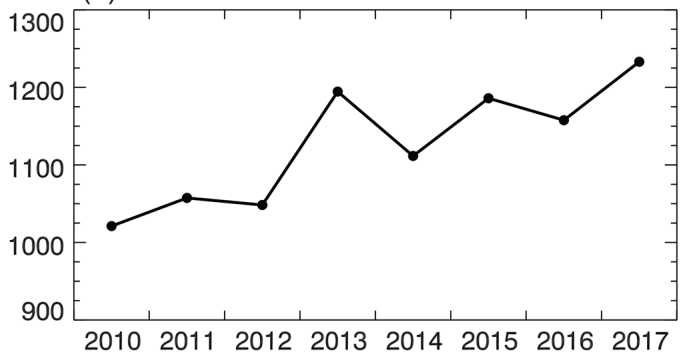

(d) Canada

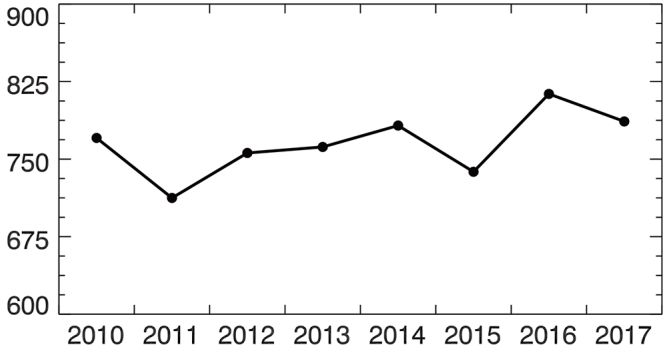

Figure 12. The 2010-2017 trends of wetland methane emissions and precipitation in CONUS and Canada. The left panels show the results from the base inversion and the mean annual emissions from the high-performance ensemble of the WetCHARTs v1.3.1 inventory (Ma et al., 2021), The 8-year WetCHARTs average is used as a prior estimate for the inversion so that the trend in the inversion results is solely from the atmospheric observations. The right panels show the annual precipitation over the wetland regions of CONUS and Canada, as determined by weighting precipitation amounts with the WetCHARTs wetland emission fluxes on their native $0.5^{\circ} \times 0.5^{\circ}$ grid. The gridded precipitation data are from the ERA-Interim re-analyses (https://www.ecmwf.int/en/forecasts/datasets/reanalysis-datasets/era-interim/, last access: 31 July $2021,0.5^{\circ} \times 0.5^{\circ}$.

pogenic. This anthropogenic emission is $30 \%$ higher than the EPA inventory of $28.7 \mathrm{Tg} \mathrm{a}^{-1}$ used as a prior estimate (EPA, 2016) and 42\% higher than the 2010-2017 mean of 26.0 $\mathrm{Tg} \mathrm{a}^{-1}$ in the most recent version of the EPA inventory (EPA, 2021). These upward corrections are largely attributed to the oil $\left(4.6 \mathrm{Tg} \mathrm{a}^{-1}\right)$ and gas $\left(9.9 \mathrm{Tg} \mathrm{a}^{-1}\right)$ sectors, which are respectively $177 \%$ and $65 \%$ higher than the EPA (2021) estimates and are mainly in large basins of the south-central US. The inversion also shows upward corrections of livestock emissions to $10.6 \mathrm{Tg} \mathrm{a}^{-1}$, which is $15 \%$ higher than the EPA estimate $\left(9.2 \mathrm{Tg} \mathrm{a}^{-1}\right)$, and of landfill emissions to $7.2 \mathrm{Tg} \mathrm{a}^{-1}$, which is $24 \%$ higher than the EPA estimate $\left(5.8 \mathrm{Tg} \mathrm{a}^{-1}\right)$.

We estimate a mean 2010-2017 emission for Canada of $16.2(13.5-17.4) \mathrm{Tg} \mathrm{a}^{-1}, 5.3(3.6-5.7) \mathrm{Tg} \mathrm{a}^{-1}$ of which is anthropogenic. This anthropogenic emission is $43 \%$ higher than the $3.7 \mathrm{Tga}^{-1}$ in the ECCC (2020) national inventory used as a prior estimate. Most of this difference is due to oil emissions, which we estimate at $1.8 \mathrm{Tg} \mathrm{a}^{-1}$; this is more than twice the ECCC estimate and mainly from production in Alberta and Saskatchewan.

We estimate a mean 2010-2017 emission for Mexico of 6.8 (5.4-6.9) $\mathrm{Tg} \mathrm{a}^{-1}, 6.0$ (4.7-6.1) $\mathrm{Tg} \mathrm{a}^{-1}$ of which is anthropogenic. This anthropogenic emission is $20 \%$ higher than the $5.0 \mathrm{Tg} \mathrm{a}^{-1}$ in the INECC (2018) national inventory used as a prior estimate. Again, most of the underestimate is due to the oil sector, specifically to oil production in the Sureste onshore region. Offshore oil emissions are lower than the INECC estimate.

We find from the inversion that anthropogenic emissions in CONUS peaked in 2014 and had no net trend over the 20102017 period $\left(+0.1(-0.1\right.$ to +0.3$\left.) \% \mathrm{a}^{-1}\right)$, in contrast with the EPA inventory that reports a steady decreasing trend of $-0.8 \% \mathrm{a}^{-1}$ over the period. The overall US emission trend reflects increases in the oil and landfill sectors, decreases in the gas sector, and flat emissions in the livestock and coal sectors. We find a decreasing trend in Canadian anthropogenic emissions of $-2.3(-2.5$ to -1.6$) \% \mathrm{a}^{-1}$ over the 2010-2017 period, mainly driven by oil and gas production. We also find a decreasing trend in Mexican anthropogenic methane emissions $\left(-3.3(-3.4\right.$ to -1.7$\left.) \% \mathrm{a}^{-1}\right)$ over the 2010-2017 period, mostly driven by the oil sector, in particular by offshore operations.

Wetlands are the main natural source of methane in all three countries. Starting from the high-performance subset of the WetCHARTs inventory ensemble as a prior estimate, our inversion yields mean wetland emission estimates for 2010-2017 of $8.4(6.4-10.6) \mathrm{Tg} \mathrm{a}^{-1}$ for CONUS, 9.9 (7.8-12.0) $\mathrm{Tg} \mathrm{a}^{-1}$ for Canada, and $0.6(0.4-0.6) \mathrm{Tg} \mathrm{a}^{-1}$ for Mexico. Wetland emissions in CONUS show a significant 
increase of $2.6(1.7-3.8) \% \mathrm{a}^{-1}$ over 2010-2017 correlated with precipitation.

Data availability. The GLOBALVIEWplus $\mathrm{CH}_{4}$ ObsPack v1.0 data product is available at https://gml.noaa.gov/ccgg/obspack/data. php?id=obspack_ch4_1_GLOBALVIEWplus_v1.0_2019-01-08 (last access: 31 July 2021). The University of Leicester GOSAT Proxy v9.0 $\mathrm{XCH}_{4}$ data are available from the Centre for Environmental Data Analysis data repository at https://doi.org/10.5285/18ef8247f52a4cb6a14013f8235cc1eb (Parker and Boesch, 2020). WetCHARTs v1.3.1 is available at the ORNL DAAC: https://doi.org/10.3334/ORNLDAAC/1915. Modeling data can be accessed by contacting the corresponding author, Xiao Lu (luxiao25@mail.sysu.edu.cn).

Author contributions. XL and DJJ designed the study. XL conducted the modeling and data analyses with contributions from HLW, JDM, ZYZ, TRS, LS, ZQ, MPS, and HN. AAB, SM, and JRW contributed to the WetCHARTs wetland emission inventory and its interpretation. RJP and HB contributed to the GOSAT satellite methane retrievals. AA contributed to the GLOBALVIEWplus $\mathrm{CH}_{4}$ ObsPack v1.0 data product. All authors provided insightful comments. XL and DJJ wrote the paper with input from all authors.

Competing interests. The contact author has declared that neither they nor their co-authors have any competing interests.

Disclaimer. Publisher's note: Copernicus Publications remains neutral with regard to jurisdictional claims in published maps and institutional affiliations.

Acknowledgements. We acknowledge all of the data providers and laboratories (https://search.datacite.org/works/10.25925/ 20190108, last access: 7 July 2021) that contributed to the GLOBALVIEWplus $\mathrm{CH}_{4}$ ObsPack v1.0 data product compiled by the NOAA Global Monitoring Laboratory. We thank the Japanese Aerospace Exploration Agency, the National Institute for Environmental Studies, and the Ministry of Environment for the GOSAT data and their continuous support as part of the joint research agreement. This research used the ALICE high-performance computing facility at the University of Leicester for the GOSAT retrievals. Part of the research was carried out at the Jet Propulsion Laboratory, California Institute of Technology, under a contract with the National Aeronautics and Space Administration. We thank Bill Irving, Erin McDuffie, and Melissa Weitz from the United States Environmental Protection Agency for helpful comments.

We acknowledge funding from the NOAA Atmospheric Chemistry, Carbon Cycle, and Climate (AC4) Program and by the NASA Carbon Monitoring System, as well as the Guangdong Major Project of Basic and Applied Basic Research and the Guangdong science and technology plan project. Robert J. Parker and Hartmut Boesch are funded via the UK National Centre for Earth Obser- vation (NCEO). We also acknowledge funding from the ESA GHG$\mathrm{CCI}$ and Copernicus $\mathrm{C} 3 \mathrm{~S}$ projects.

Financial support. This research has been supported by the Guangdong Major Project of Basic and Applied Basic Research (grant no. 2020B0301030004), the Guangdong science and technology plan project (grant no. 2019B121201002), the NOAA Atmospheric Chemistry, Carbon Cycle, and Climate (AC4) Program (grant no. NA19OAR4310173), NASA Carbon Monitoring System (grant no. 80NSSC18K0178), and the UK National Centre for Earth Observation (grant nos NE/R016518/1 and NE/N018079/1).

Review statement. This paper was edited by Joshua Fu and reviewed by Lena Höglund-Isaksson and one anonymous referee.

\section{References}

Alvarez, R. A., Zavala-Araiza, D., Lyon, D. R., Allen, D. T., Barkley, Z. R., Brandt, A. R., Davis, K. J., Herndon, S. C., Jacob, D. J., Karion, A., Kort, E. A., Lamb, B. K., Lauvaux, T., Maasakkers, J. D., Marchese, A. J., Omara, M., Pacala, S. W., Peischl, J., Robinson, A. L., Shepson, P. B., Sweeney, C., Townsend-Small, A., Wofsy, S. C., and Hamburg, S. P.: Assessment of methane emissions from the U.S. oil and gas supply chain, Science, 361, 186-188, https://doi.org/10.1126/science.aar7204, 2018.

Atherton, E., Risk, D., Fougère, C., Lavoie, M., Marshall, A., Werring, J., Williams, J. P., and Minions, C.: Mobile measurement of methane emissions from natural gas developments in northeastern British Columbia, Canada, Atmos. Chem. Phys., 17, 1240512420, https://doi.org/10.5194/acp-17-12405-2017, 2017.

Baray, S., Darlington, A., Gordon, M., Hayden, K. L., Leithead, A., Li, S.-M., Liu, P. S. K., Mittermeier, R. L., Moussa, S. G., O’Brien, J., Staebler, R., Wolde, M., Worthy, D., and McLaren, R.: Quantification of methane sources in the Athabasca Oil Sands Region of Alberta by aircraft mass balance, Atmos. Chem. Phys., 18, 7361-7378, https://doi.org/10.5194/acp-18-7361-2018, 2018.

Baray, S., Jacob, D. J., Maasakkers, J. D., Sheng, J.-X., Sulprizio, M. P., Jones, D. B. A., Bloom, A. A., and McLaren, R.: Estimating 2010-2015 anthropogenic and natural methane emissions in Canada using ECCC surface and GOSAT satellite observations, Atmos. Chem. Phys., 21, 18101-18121, https://doi.org/10.5194/acp-21-18101-2021, 2021.

Bloom, A. A., Bowman, K. W., Lee, M., Turner, A. J., Schroeder, R., Worden, J. R., Weidner, R., McDonald, K. C., and Jacob, D. J.: A global wetland methane emissions and uncertainty dataset for atmospheric chemical transport models (WetCHARTs version 1.0), Geosci. Model Dev., 10, 2141-2156, https://doi.org/10.5194/gmd-10-2141-2017, 2017.

Brasseur, G. P. and Jacob, D. J.: Modeling of Atmospheric Chemistry, Cambridge University Press, Cambridge, UK, https://doi.org/10.1017/9781316544754, 2017.

Calisesi, Y., Soebijanta, V. T., and van Oss, R.: Regridding of remote soundings: Formulation and application to 
ozone profile comparison, J. Geophys. Res., 110, D23306, https://doi.org/10.1029/2005jd006122, 2005.

Chan, E., Worthy, D. E. J., Chan, D., Ishizawa, M., Moran, M. D., Delcloo, A., and Vogel, F.: Eight-Year Estimates of Methane Emissions from Oil and Gas Operations in Western Canada Are Nearly Twice Those Reported in Inventories, Environ. Sci. Technol., 54, 14899-14909, https://doi.org/10.1021/acs.est.0c04117, 2020.

Cooperative Global Atmospheric Data Integration Project: Multi-laboratory compilation of atmospheric methane data for the period 1957-2017, obspack_ch4_1_GLOBALVIEWplus_v1.0_2019_01_08, NOAA Earth System Research Laboratory, Global Monitoring Laboratory, https://doi.org/10.25925/20190108 (last access: 17 July 2020), 2019.

Climate TRACE: available at: https://www.climatetrace.org/, last access: 31 July 2021.

Cusworth, D. H., Jacob, D. J., Sheng, J.-X., Benmergui, J., Turner, A. J., Brandman, J., White, L., and Randles, C. A.: Detecting high-emitting methane sources in oil/gas fields using satellite observations, Atmos. Chem. Phys., 18, 16885-16896, https://doi.org/10.5194/acp-18-16885-2018, 2018.

Cusworth, D. H., Duren, R. M., Thorpe, A. K., Olson-Duvall, W., Heckler, J., Chapman, J. W., Eastwood, M. L., Helmlinger, M. C., Green, R. O., Asner, G. P., Dennison, P. E., and Miller, C. E.: Intermittency of large methane emitters in the Permian Basin, Environ. Sci. Tech. Let., 8, 567-573, https://doi.org/10.1021/acs.estlett.1c00173, 2021.

Environment and Climate Change Canada (ECCC): Canada to reduce emissions from oil and gas industry, Environment and Climate Change Canada (ECCC), Gatineau QC, available at: https: //www.canada.ca/en/environment-climate-change/news/2017/ 05/canada_to_reduceemissionsfromoilandgasindustry.html (last access: 6 April 2021), 2017.

Environment and Climate Change Canada (ECCC): National Inventory Report 1990-2018: Greenhouse Gas Sources and Sinks in Canada, Environment and Climate Change Canada (ECCC), Gatineau QC, available at: http://publications.gc.ca/pub?id=9. 506002\&sl=0 (last access: 6 April 2021), 2020a.

Environment and Climate Change Canada (ECCC): Canada's National Report on Black Carbon and Methane: Canada's Third Biennial Report to the Arctic Council, Environment and Climate Change Canada, available at: https://publications.gc.ca/ collections/collection_2021/eccc/En11-18-2021-eng.pdf, (last access: 31 July 2021), 2020b.

Environment and Climate Change Canada (ECCC): National Inventory Report 1990-2019: Greenhouse Gas Sources and Sinks in Canada, Environment and Climate Change Canada (ECCC), Gatineau QC, available at: https://publications.gc.ca/site/eng/9. 506002/publication.html, last access: 31 July 2021.

EPA: Inventory of US Greenhouse Gas Emissions and Sinks: 1990-2014, U.S. Environmental Protection Agency (EPA), available at: https://www.epa.gov/ghgemissions/ inventory-us-greenhouse-gas-emissions-and-sinks-1990-2014 (last access: 6 April 2021), 2016.

EPA: Inventory of US Greenhouse Gas Emissions and Sinks: 1990-2019, U.S. Environmental Protection Agency (EPA), available at: https://www.epa.gov/ghgemissions/ inventory-us-greenhouse-gas-emissions-and-sinks-1990-2019, last access: 31 July 2021.

Frankenberg, C., Thorpe, A. K., Thompson, D. R., Hulley, G., Kort, E. A., Vance, N., Borchardt, J., Krings, T., Gerilowski, K., Sweeney, C., Conley, S., Bue, B. D., Aubrey, A. D., Hook, S., and Green, R. O.: Airborne methane remote measurements reveal heavy-tail flux distribution in Four Corners region, P. Natl. Acad. Sci. USA, 113, 9734-9739, https://doi.org/10.1073/pnas.1605617113, 2016.

Gelaro, R., McCarty, W., Suárez, M. J., Todling, R., Molod, A., Takacs, L., Randles, C. A., Darmenov, A., Bosilovich, M. G., Reichle, R., Wargan, K., Coy, L., Cullather, R., Draper, C., Akella, S., Buchard, V., Conaty, A., da Silva, A. M., Gu, W., Kim, G.-K., Koster, R., Lucchesi, R., Merkova, D., Nielsen, J. E., Partyka, G., Pawson, S., Putman, W., Rienecker, M., Schubert, S. D., Sienkiewicz, M., and Zhao, B.: The Modern-Era Retrospective Analysis for Research and Applications, Version 2 (MERRA-2), J. Climate, 30, 5419-5454, https://doi.org/10.1175/jcli-d-16-0758.1, 2017.

Gordon D. and Reuland, R.: Personal communication regarding Climate TRACE provisional national results using the Oil Climate Index Plus Gas models, 17 July 2021.

Gordon, D., Brandt, A., Bergerson, J., and Koomey, J.: Know Your Oil: Creating a Global Oil-Climate Index, Carnegie Endowment for International Peace, available at: https://carnegieendowment.org/2015/03/11/ know-your-oil-creating-global-oil-climate-index-pub-59285 (last access: 31 July 2021), 2015.

Heald, C. L., Jacob, D. J., Jones, D. B. A., Palmer, P. I., Logan, J. A., Streets, D. G., Sachse, G. W., Gille, J. C., Hoffman, R. N., and Nehrkorn, T.: Comparative inverse analysis of satellite (MOPITT) and aircraft (TRACE-P) observations to estimate Asian sources of carbon monoxide, J. Geophys. Res., 109, D23306, https://doi.org/10.1029/2004jd005185, 2004.

Houweling, S., Bergamaschi, P., Chevallier, F., Heimann, M., Kaminski, T., Krol, M., Michalak, A. M., and Patra, P.: Global inverse modeling of $\mathrm{CH}_{4}$ sources and sinks: an overview of methods, Atmos. Chem. Phys., 17, 235-256, https://doi.org/10.5194/acp-17-235-2017, 2017.

INECC and SEMARNAT 2018 México: Inventario Nacional de Emisiones de Gases y Compuesto de Efecto Invernadero 1990 2015 (INEGyCEI) Instituto Nacional de Ecología y Cambio Climático (INECC) and Secretaría de Medio Ambiente y Recursos Naturales (SEMARNAT), 2018.

Iowa Department of Natural Resources: The online Animal Feeding Operations database, available at: https://programs.iowadnr.gov/ animalfeedingoperations/ (last access: 11 June 2020), 2017.

Johnson, M. R., Tyner, D. R., Conley, S., Schwietzke, S., and Zavala-Araiza, D.: Comparisons of Airborne Measurements and Inventory Estimates of Methane Emissions in the Alberta Upstream Oil and Gas Sector, Environ. Sci. Technol., 51, 1300813017, https://doi.org/10.1021/acs.est.7b03525, 2017.

Karion, A., Sweeney, C., Kort, E. A., Shepson, P. B., Brewer, A., Cambaliza, M., Conley, S. A., Davis, K., Deng, A., Hardesty, M., Herndon, S. C., Lauvaux, T., Lavoie, T., Lyon, D., Newberger, T., Petron, G., Rella, C., Smith, M., Wolter, S., Yacovitch, T. I., and Tans, P.: Aircraft-Based Estimate of Total Methane Emissions from the Barnett Shale Region, Environ. Sci. Technol., 49, 8124 8131, https://doi.org/10.1021/acs.est.5b00217, 2015. 
Kirschke, S., Bousquet, P., Ciais, P., Saunois, M., Canadell, J. G., Dlugokencky, E. J., Bergamaschi, P., Bergmann, D., Blake, D. R., Bruhwiler, L., Cameron-Smith, P., Castaldi, S., Chevallier, F., Feng, L., Fraser, A., Heimann, M., Hodson, E. L., Houweling, S., Josse, B., Fraser, P. J., Krummel, P. B., Lamarque, J.-F., Langenfelds, R. L., Le Quéré, C., Naik, V., O’Doherty, S., Palmer, P. I., Pison, I., Plummer, D., Poulter, B., Prinn, R. G., Rigby, M., Ringeval, B., Santini, M., Schmidt, M., Shindell, D. T., Simpson, I. J., Spahni, R., Steele, L. P., Strode, S. A., Sudo, K., Szopa, S., van der Werf, G. R., Voulgarakis, A., van Weele, M., Weiss, R. F., Williams, J. E., and Zeng, G.: Three decades of global methane sources and sinks, Nat. Geosci., 6, 813-823, https://doi.org/10.1038/ngeo1955, 2013.

Kuze, A., Suto, H., Shiomi, K., Kawakami, S., Tanaka, M., Ueda, Y., Deguchi, A., Yoshida, J., Yamamoto, Y., Kataoka, F., Taylor, T. E., and Buijs, H. L.: Update on GOSAT TANSOFTS performance, operations, and data products after more than 6 years in space, Atmos. Meas. Tech., 9, 2445-2461, https://doi.org/10.5194/amt-9-2445-2016, 2016.

Lan, X., Tans, P., Sweeney, C., Andrews, A., Dlugokencky, E., Schwietzke, S., Kofler, J., McKain, K., Thoning, K., Crotwell, M., Montzka, S., Miller, B. R., and Biraud, S. C.: Long-Term Measurements Show Little Evidence for Large Increases in Total U. S. Methane Emissions Over the Past Decade, Geophys. Res. Lett., 46, 4991-4999, https://doi.org/10.1029/2018gl081731, 2019.

Lu, X., Jacob, D. J., Zhang, Y., Maasakkers, J. D., Sulprizio, M. P., Shen, L., Qu, Z., Scarpelli, T. R., Nesser, H., Yantosca, R. M., Sheng, J., Andrews, A., Parker, R. J., Boesch, H., Bloom, A. A., and $\mathrm{Ma}$, S.: Global methane budget and trend, 2010-2017: complementarity of inverse analyses using in situ (GLOBALVIEWplus $\mathrm{CH}_{4}$ ObsPack) and satellite (GOSAT) observations, Atmos. Chem. Phys., 21, 4637-4657, https://doi.org/10.5194/acp21-4637-2021, 2021.

Lyon, D. R., Zavala-Araiza, D., Alvarez, R. A., Harriss, R., Palacios, V., Lan, X., Talbot, R., Lavoie, T., Shepson, P., Yacovitch, T. I., Herndon, S. C., Marchese, A. J., Zimmerle, D., Robinson, A. L., and Hamburg, S. P.: Constructing a Spatially Resolved Methane Emission Inventory for the Barnett Shale Region, Environ. Sci. Technol., 49, 8147-8157, https://doi.org/10.1021/es506359c, 2015.

Ma, S., Worden, J. R., Bloom, A. A., Zhang, Y., Poulter, B., Cusworth, D. H., Yin, Y., Pandey, S., Maasakkers, J. D., Lu, X., Shen, L., Sheng, J., Frankenberg, C., Miller, C. E., and Jacob, D. J.: Satellite Constraints on the Latitudinal Distribution and Temperature Sensitivity of Wetland Methane Emissions, AGU Advances, 2, e2021AV000408, https://doi.org/10.1029/2021av000408, 2021.

Maasakkers, J. D., Jacob, D. J., Sulprizio, M. P., Turner, A. J., Weitz, M., Wirth, T., Hight, C., DeFigueiredo, M., Desai, M., Schmeltz, R., Hockstad, L., Bloom, A. A., Bowman, K. W., Jeong, S., and Fischer, M. L.: Gridded National Inventory of U. S. Methane Emissions, Environ. Sci. Technol., 50, 1312313133, https://doi.org/10.1021/acs.est.6b02878, 2016.

Maasakkers, J. D., Jacob, D. J., Sulprizio, M. P., Scarpelli, T. R., Nesser, H., Sheng, J.-X., Zhang, Y., Hersher, M., Bloom, A. A., Bowman, K. W., Worden, J. R., Janssens-Maenhout, G., and Parker, R. J.: Global distribution of methane emissions, emission trends, and $\mathrm{OH}$ concentrations and trends inferred from an inversion of GOSAT satellite data for 2010-2015, Atmos. Chem. Phys., 19, 7859-7881, https://doi.org/10.5194/acp-197859-2019, 2019.

Maasakkers, J. D., Jacob, D. J., Sulprizio, M. P., Scarpelli, T. R., Nesser, H., Sheng, J., Zhang, Y., Lu, X., Bloom, A. A., Bowman, K. W., Worden, J. R., and Parker, R. J.: 2010-2015 North American methane emissions, sectoral contributions, and trends: a high-resolution inversion of GOSAT observations of atmospheric methane, Atmos. Chem. Phys., 21, 4339-4356, https://doi.org/10.5194/acp-21-4339-2021, 2021.

Masnadi, M., El-Houjeiri, H., Schunack, D., Yunpo, L., Englander, J., Badahdah, A., Monfort, J., Anderson, J., Wallington, T., Bergerson, B., Gordon, D., Koomey, J., Przesmitzki, S., Azevedo, I., Bi. X., Duffy, J., Heath, G., Keoleian, G., McGlade, C., Meehan, N., Yeh, S., You, F., Wang, M., and Brandt, A.: Global Carbon Intensity of Crude Oil Production, Science, 361, 851-853, https://doi.org/10.1126/science.aar6859, 2018.

Miller, S. M., Wofsy, S. C., Michalak, A. M., Kort, E. A., Andrews, A. E., Biraud, S. C., Dlugokencky, E. J., Eluszkiewicz, J., Fischer, M. L., Janssens-Maenhout, G., Miller, B. R., Miller, J. B., Montzka, S. A., Nehrkorn, T., and Sweeney, C.: Anthropogenic emissions of methane in the United States, P. Natl. Acad. Sci. USA, 110, 20018-20022, https://doi.org/10.1073/pnas.1314392110, 2013.

Miller, S. M., Michalak, A. M., and Levi, P. J.: Atmospheric inverse modeling with known physical bounds: an example from trace gas emissions, Geosci. Model Dev., 7, 303-315, https://doi.org/10.5194/gmd-7-303-2014, 2014.

Murguia-Flores, F., Arndt, S., Ganesan, A. L., MurrayTortarolo, G., and Hornibrook, E. R. C.: Soil Methanotrophy Model (MeMo v1.0): a process-based model to quantify global uptake of atmospheric methane by soil, Geosci. Model Dev., 11, 2009-2032, https://doi.org/10.5194/gmd-11-2009-2018, 2018.

Parker, R. and Boesch, H.: University of Leicester GOSAT Proxy XCH4 v9.0. Centre for Environmental Data Analysis, https://doi.org/10.5285/18ef8247f52a4cb6a14013f8235cc1eb (last access: $31 \mathrm{Jul}$ 2021), 2020.

Parker, R. J., Webb, A., Boesch, H., Somkuti, P., Barrio Guillo, R., Di Noia, A., Kalaitzi, N., Anand, J. S., Bergamaschi, P., Chevallier, F., Palmer, P. I., Feng, L., Deutscher, N. M., Feist, D. G., Griffith, D. W. T., Hase, F., Kivi, R., Morino, I., Notholt, J., Oh, Y.-S., Ohyama, H., Petri, C., Pollard, D. F., Roehl, C., Sha, M. K., Shiomi, K., Strong, K., Sussmann, R., Té, Y., Velazco, V. A., Warneke, T., Wennberg, P. O., and Wunch, D.: A decade of GOSAT Proxy satellite $\mathrm{CH}_{4}$ observations, Earth Syst. Sci. Data, 12, 3383-3412, https://doi.org/10.5194/essd-12-33832020, 2020a.

Parker, R. J., Wilson, C., Bloom, A. A., Comyn-Platt, E., Hayman, G., McNorton, J., Boesch, H., and Chipperfield, M. P. Exploring constraints on a wetland methane emission ensemble (WetCHARTs) using GOSAT observations, Biogeosciences, 17 , 5669-5691, https://doi.org/10.5194/bg-17-5669-2020, 2020 b.

Peischl, J., Ryerson, T. B., Aikin, K. C., Gouw, J. A., Gilman, J. B., Holloway, J. S., Lerner, B. M., Nadkarni, R., Neuman, J. A., Nowak, J. B., Trainer, M., Warneke, C., and Parrish, D. D.: Quantifying atmospheric methane emissions from the Haynesville, Fayetteville, and northeastern Marcellus shale 
gas production regions, J. Geophys. Res., 120, 2119-2139, https://doi.org/10.1002/2014jd022697, 2015.

Qu, Z., Jacob, D. J., Shen, L., Lu, X., Zhang, Y., Scarpelli, T. R., Nesser, H., Sulprizio, M. P., Maasakkers, J. D., Bloom, A. A., Worden, J. R., Parker, R. J., and Delgado, A. L.: Global distribution of methane emissions: a comparative inverse analysis of observations from the TROPOMI and GOSAT satellite instruments, Atmos. Chem. Phys., 21, 14159-14175, https://doi.org/10.5194/acp-21-14159-2021, 2021.

Ren, X., Hall, D. L., Vinciguerra, T., Benish, S. E., Stratton, P. R., Ahn, D., Hansford, J. R., Cohen, M. D., Sahu, S., He, H., Grimes, C., Fuentes, J. D., Shepson, P. B., Salawitch, R. J., Ehrman, S. H., and Dickerson, R. R.: Methane Emissions from the Marcellus Shale in Southwestern Pennsylvania and Northern West Virginia Based on Airborne Measurements, J. Geophys. Res., 124, 1862-1878, https://doi.org/10.1029/2018jd029690, 2019.

Robertson, A. M., Edie, R., Field, R. A., Lyon, D., McVay, R., Omara, M., Zavala-Araiza, D., and Murphy, S. M.: New Mexico Permian Basin Measured Well Pad Methane Emissions Are a Factor of 5-9 Times Higher Than U.S. EPA Estimates, Environ. Sci. Technol., 54, 13926-13934, https://doi.org/10.1021/acs.est.0c02927, 2020.

Rodgers, C. D.: Inverse Methods for Atmospheric Sounding: Theory and Practice, World Scientific, River Edge, USA, 2000.

Saunois, M., Stavert, A. R., Poulter, B., Bousquet, P., Canadell, J. G., Jackson, R. B., Raymond, P. A., Dlugokencky, E. J., Houweling, S., Patra, P. K., Ciais, P., Arora, V. K., Bastviken, D., Bergamaschi, P., Blake, D. R., Brailsford, G., Bruhwiler, L., Carlson, K. M., Carrol, M., Castaldi, S., Chandra, N., Crevoisier, C., Crill, P. M., Covey, K., Curry, C. L., Etiope, G., Frankenberg, C., Gedney, N., Hegglin, M. I., Höglund-Isaksson, L., Hugelius, G., Ishizawa, M., Ito, A., Janssens-Maenhout, G., Jensen, K. M., Joos, F., Kleinen, T., Krummel, P. B., Langenfelds, R. L., Laruelle, G. G., Liu, L., Machida, T., Maksyutov, S., McDonald, K. C., McNorton, J., Miller, P. A., Melton, J. R., Morino, I., Müller, J., Murguia-Flores, F., Naik, V., Niwa, Y., Noce, S., O’Doherty, S., Parker, R. J., Peng, C., Peng, S., Peters, G. P., Prigent, C., Prinn, R., Ramonet, M., Regnier, P., Riley, W. J., Rosentreter, J. A., Segers, A., Simpson, I. J., Shi, H., Smith, S. J., Steele, L. P., Thornton, B. F., Tian, H., Tohjima, Y., Tubiello, F. N., Tsuruta, A., Viovy, N., Voulgarakis, A., Weber, T. S., van Weele, M., van der Werf, G. R., Weiss, R. F., Worthy, D., Wunch, D., Yin, Y., Yoshida, Y., Zhang, W., Zhang, Z., Zhao, Y., Zheng, B., Zhu, Q., Zhu, Q., and Zhuang, Q.: The Global Methane Budget 2000-2017, Earth Syst. Sci. Data, 12, 1561-1623, https://doi.org/10.5194/essd-121561-2020, 2020.

Scarpelli, T. R., Jacob, D. J., Octaviano Villasana, C. A., Ramírez Hernández, I. F., Cárdenas Moreno, P. R., Cortés Alfaro, E. A., García García, M. Á., and Zavala-Araiza, D.: A gridded inventory of anthropogenic methane emissions from Mexico based on Mexico's national inventory of greenhouse gases and compounds, Environ. Res. Lett., 15, 105015, https://doi.org/10.1088/1748-9326/abb42b, 2020.

Scarpelli, T. R., Jacob, D. J., Moran, M., Reuland, F., and Gordon, D.: A gridded inventory of Canada's anthro- pogenic methane emissions, Environ. Res. Lett., 17, 014007 , https://doi.org/10.1088/1748-9326/ac40b1, 2021.

Shen, L., Zavala-Araiza, D., Gautam, R., Omara, M., Scarpelli, T., Sheng, J., Sulprizio, M. P., Zhuang, J., Zhang, Y., Qu, Z., Lu, X., Hamburg, S. P., and Jacob, D. J.: Unravelling a large methane emission discrepancy in Mexico using satellite observations, Remote Sens. Environ., 260, 112461, https://doi.org/10.1016/j.rse.2021.112461, 2021.

Sheng, J.-X., Jacob, D. J., Turner, A. J., Maasakkers, J. D., Benmergui, J., Bloom, A. A., Arndt, C., Gautam, R., Zavala-Araiza, D., Boesch, H., and Parker, R. J.: 2010-2016 methane trends over Canada, the United States, and Mexico observed by the GOSAT satellite: contributions from different source sectors, Atmos. Chem. Phys., 18, 12257-12267, https://doi.org/10.5194/acp-1812257-2018, 2018a.

Sheng, J.-X., Jacob, D. J., Turner, A. J., Maasakkers, J. D., Sulprizio, M. P., Bloom, A. A., Andrews, A. E., and Wunch, D.: High-resolution inversion of methane emissions in the Southeast US using SEAC ${ }^{4} \mathrm{RS}$ aircraft observations of atmospheric methane: anthropogenic and wetland sources, Atmos. Chem. Phys., 18, 6483-6491, https://doi.org/10.5194/acp-186483-2018, 2018b.

Sun, W., Wang, X., DeCarolis, J. F., and Barlaz, M. A.: Evaluation of optimal model parameters for prediction of methane generation from selected U. S. landfills, Waste Manage., 91, 120-127, https://doi.org/10.1016/j.wasman.2019.05.004, 2019.

Turner, A. J. and Jacob, D. J.: Balancing aggregation and smoothing errors in inverse models, Atmos. Chem. Phys., 15, 7039-7048, https://doi.org/10.5194/acp-15-7039-2015, 2015.

Turner, A. J., Jacob, D. J., Wecht, K. J., Maasakkers, J. D., Lundgren, E., Andrews, A. E., Biraud, S. C., Boesch, H., Bowman, K. W., Deutscher, N. M., Dubey, M. K., Griffith, D. W. T., Hase, F., Kuze, A., Notholt, J., Ohyama, H., Parker, R., Payne, V. H., Sussmann, R., Sweeney, C., Velazco, V. A., Warneke, T., Wennberg, P. O., and Wunch, D.: Estimating global and North American methane emissions with high spatial resolution using GOSAT satellite data, Atmos. Chem. Phys., 15, 7049 7069, https://doi.org/10.5194/acp-15-7049-2015, 2015.

Turner, A. J., Jacob, D. J., Benmergui, J., Wofsy, S. C., Maasakkers, J. D., Butz, A., Hasekamp, O., and Biraud, S. C.: A large increase in US methane emissions over the past decade inferred from satellite data and surface observations, Geophys. Res. Lett., 43, 2218-2224, https://doi.org/10.1002/2016GL067987, 2016.

Turner, A. J., Jacob, D. J., Benmergui, J., Brandman, J., White, L., and Randles, C. A.: Assessing the capability of different satellite observing configurations to resolve the distribution of methane emissions at kilometer scales, Atmos. Chem. Phys., 18, 82658278, https://doi.org/10.5194/acp-18-8265-2018, 2018.

Tyner, D. R. and Johnson, M. R.: Where the Methane Is-Insights from Novel Airborne LiDAR Measurements Combined with Ground Survey Data, Environ. Sci. Technol., 55, 9773-9783, https://doi.org/10.1021/acs.est.1c01572, 2021.

UNFCCC: United Nations Framework Convention on Climate Change, United Nations, New York, 9 May 1992.

van der Werf, G. R., Randerson, J. T., Giglio, L., van Leeuwen, T. T., Chen, Y., Rogers, B. M., Mu, M., van Marle, M. J. E., Morton, D. C., Collatz, G. J., Yokelson, R. J., and Kasibhatla, P. S.: Global fire emissions estimates during 1997-2016, Earth Syst. 
Sci. Data, 9, 697-720, https://doi.org/10.5194/essd-9-697-2017, 2017.

Wang, X., Nagpure, A. S., DeCarolis, J. F., and Barlaz, M. A.: Using observed data to improve estimated methane collection from select U. S. landfills, Environ. Sci. Technol., 47, 3251-3257, https://doi.org/10.1021/es304565m, 2013.

Watts, J. D., Kimball, J. S., Bartsch, A., and McDonald, K. C.: Surface water inundation in the boreal-Arctic: potential impacts on regional methane emissions, Environ. Res. Lett., 9, 075001, https://doi.org/10.1088/1748-9326/9/7/075001, 2014.

Wecht, K. J., Jacob, D. J., Frankenberg, C., Jiang, Z., and Blake, D. R.: Mapping of North American methane emissions with high spatial resolution by inversion of SCIAMACHY satellite data, J. Geophys. Res., 119, 7741-7756, https://doi.org/10.1002/2014jd021551, 2014.

Wunch, D., Toon, G. C., Blavier, J.-F. L., Washenfelder, R. A., Notholt, J., Connor, B. J., Griffith, D. W. T., Sherlock, V., and Wennberg, P. O.: The Total Carbon Column Observing Network, Philos. T. R. Soc. A, 369, 2087-2112, https://doi.org/10.1098/rsta.2010.0240, 2011.

Yu, X., Millet, D. B., Wells, K. C., Henze, D. K., Cao, H., Griffis, T. J., Kort, E. A., Plant, G., Deventer, M. J., Kolka, R. K., Roman, D. T., Davis, K. J., Desai, A. R., Baier, B. C., McKain, K., Czarnetzki, A. C., and Bloom, A. A.: Aircraft-based inversions quantify the importance of wetlands and livestock for Upper Midwest methane emissions, Atmos. Chem. Phys., 21, 951-971, https://doi.org/10.5194/acp-21-951-2021, 2021.

Zavala-Araiza, D., Lyon, D. R., Alvarez, R. A., Davis, K. J., Harriss, R., Herndon, S. C., Karion, A., Kort, E. A., Lamb, B. K., Lan, X., Marchese, A. J., Pacala, S. W., Robinson, A. L., Shepson, P. B., Sweeney, C., Talbot, R., TownsendSmall, A., Yacovitch, T. I., Zimmerle, D. J., and Hamburg, S. P.: Reconciling divergent estimates of oil and gas methane emissions, P. Natl. Acad. Sci. USA, 112, 15597-15602, https://doi.org/10.1073/pnas.1522126112, 2015.
Zavala-Araiza, D., Omara, M., Gautam, R., Smith, M. L., Pandey, S., Aben, I., Almanza-Veloz, V., Conley, S., Houweling, S., Kort, E. A., Maasakkers, J. D., Molina, L. T., Pusuluri, A., Scarpelli, T., Schwietzke, S., Shen, L., Zavala, M., and Hamburg, S. P.: A tale of two regions: methane emissions from oil and gas production in offshore/onshore Mexico, Environ. Res. Lett., 16, 024019, https://doi.org/10.1088/1748-9326/abceeb, 2021.

Zhang, Y., Jacob, D. J., Maasakkers, J. D., Sulprizio, M. P., Sheng, J.-X., Gautam, R., and Worden, J.: Monitoring global tropospheric $\mathrm{OH}$ concentrations using satellite observations of atmospheric methane, Atmos. Chem. Phys., 18, 15959-15973, https://doi.org/10.5194/acp-18-15959-2018, 2018.

Zhang, Y., Gautam, R., Zavala-Araiza, D., Jacob, D. J., Zhang, R., Zhu, L., Sheng, J. X., and Scarpelli, T.: Satellite-Observed Changes in Mexico's Offshore Gas Flaring Activity Linked to Oil/Gas Regulations, Geophys. Res. Lett., 46, 1879-1888, https://doi.org/10.1029/2018gl081145, 2019.

Zhang, Y., Gautam, R., Pandey, S., Omara, M., Maasakkers, J. D., Sadavarte, P., Lyon, D., Nesser, H., Sulprizio, M. P., Varon, D. J., Zhang, R., Houweling, S., Zavala-Araiza, D., Alvarez, R. A., Lorente, A., Hamburg, S. P., Aben, I., and Jacob, D. J.: Quantifying methane emissions from the largest oil-producing basin in the United States from space, Science Advances, 6, eaaz5120, https://doi.org/10.1126/sciadv.aaz5120, 2020.

Zhang, Y., Jacob, D. J., Lu, X., Maasakkers, J. D., Scarpelli, T. R., Sheng, J.-X., Shen, L., Qu, Z., Sulprizio, M. P., Chang, J., Bloom, A. A., Ma, S., Worden, J., Parker, R. J., and Boesch, H.: Attribution of the accelerating increase in atmospheric methane during 2010-2018 by inverse analysis of GOSAT observations, Atmos. Chem. Phys., 21, 3643-3666, https://doi.org/10.5194/acp-21-3643-2021, 2021. 